\title{
NASA's Ares I and Ares V Launch Vehicles - Effective Space Operations Through Efficient Ground Operations
}

\author{
Christopher E. Singer ${ }^{1}$ \\ Daniel L. Dumbacher ${ }^{2}$ \\ Garry M. Lyles ${ }^{3}$ \\ Jay F. Onken ${ }^{4}$ \\ NASA Marshall Space Flight Center, Alabama 35812 \\ United States
}

\begin{abstract}
The United States (U.S.) is charting a renewed course for lunar exploration, with the fielding of a new human-rated space transportation system to replace the venerable Space Shuttle, which will be retired after it completes its missions of building the International Space Station (ISS) and servicing the Hubble Space Telescope. Powering the future of space-based scientific exploration will be the Ares I Crew Launch Vehicle, which will transport the Orion Crew Exploration Vehicle to orbit where it will rendezvous with the Altair Lunar Lander, which will be delivered by the Ares V Cargo Launch Vehicle (fig. 1). This configuration will empower rekindled investigation of Earth's natural satellite in the not too distant future. This new exploration infrastructure, developed by the National Aeronautics and Space Administration (NASA), will allow astronauts to leave low-Earth orbit (LEO) for extended lunar missions and preparation for the first long-distance journeys to Mars. All space-based operations - to LEO and beyond - are controlled from Earth. NASA's philosophy is to deliver safe, reliable, and cost-effective architecture solutions to sustain this multi-billiondollar program across several decades. Leveraging 50 years of lessons learned, NASA is partnering with private industry and academia, while building on proven hardware experience. This paper outlines a few ways that the Engineering Directorate at NASA's Marshall Space Flight Center is working with the Constellation Program and its project offices to streamline ground operations concepts by designing for operability, which reduces lifecycle costs and promotes sustainable space exploration.
\end{abstract}

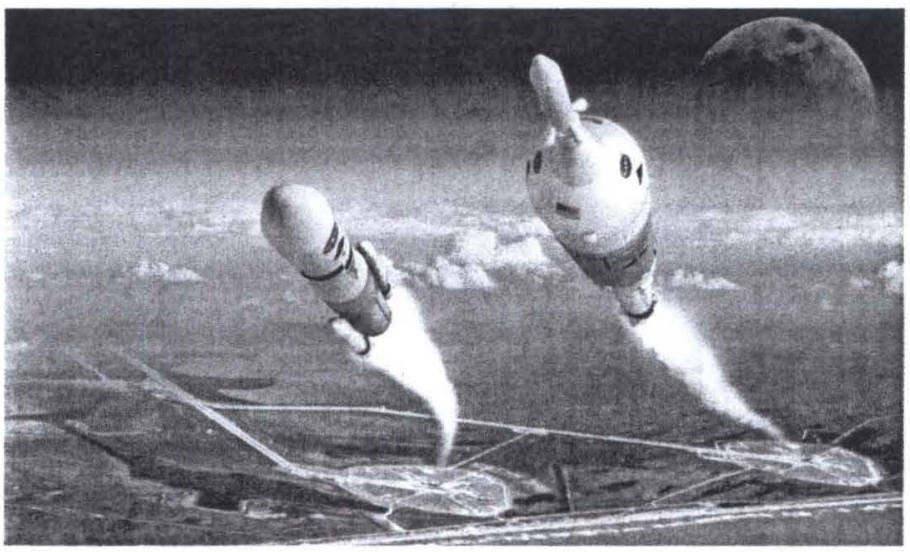

Fig. 1. NASA concept of the Ares I/Orion (right) and the Ares V.

${ }^{1}$ Deputy Director, Engineering Directorate, Mail Stop: ED01, Member

${ }^{2}$ Director, Engineering Directorate, Mail Stop: ED01, Member

${ }^{3}$ Associate Director for Technical Management, Engineering Directorate, Mail Stop: ED01, Member

${ }^{4}$ Manager for Mission Operations, Engineering Directorate, Mail Stop: EO01. 


\section{Transitioning and Transforming: \\ From the Space Shuttle Era to the Constellation Program Architecture}

A new era of space operations is on the horizon. The Space Shuttle is the world's only reusable spacecraft, carrying both crew and cargo to Earth orbit and returning to either the Kennedy Space Center in Florida or the Dryden Flight Research Center in California. It is also the only vehicle capable of completing the International Space Station assembly. In 2007, the European Space Agency's Columbus laboratory module was launched and successfully installed on the Station (fig. 2), and in 2008, Canada's Dextre robotic arm and the Japanese Aerospace Exploration Agency's Kibo laboratory are slated for service. Also in 2008, a servicing mission to the Hubble Space Telescope is manifested, underscoring the versatility of Shuttle capabilities and the types of tasks that can only be performed with the adroitness of the human hand and brain.

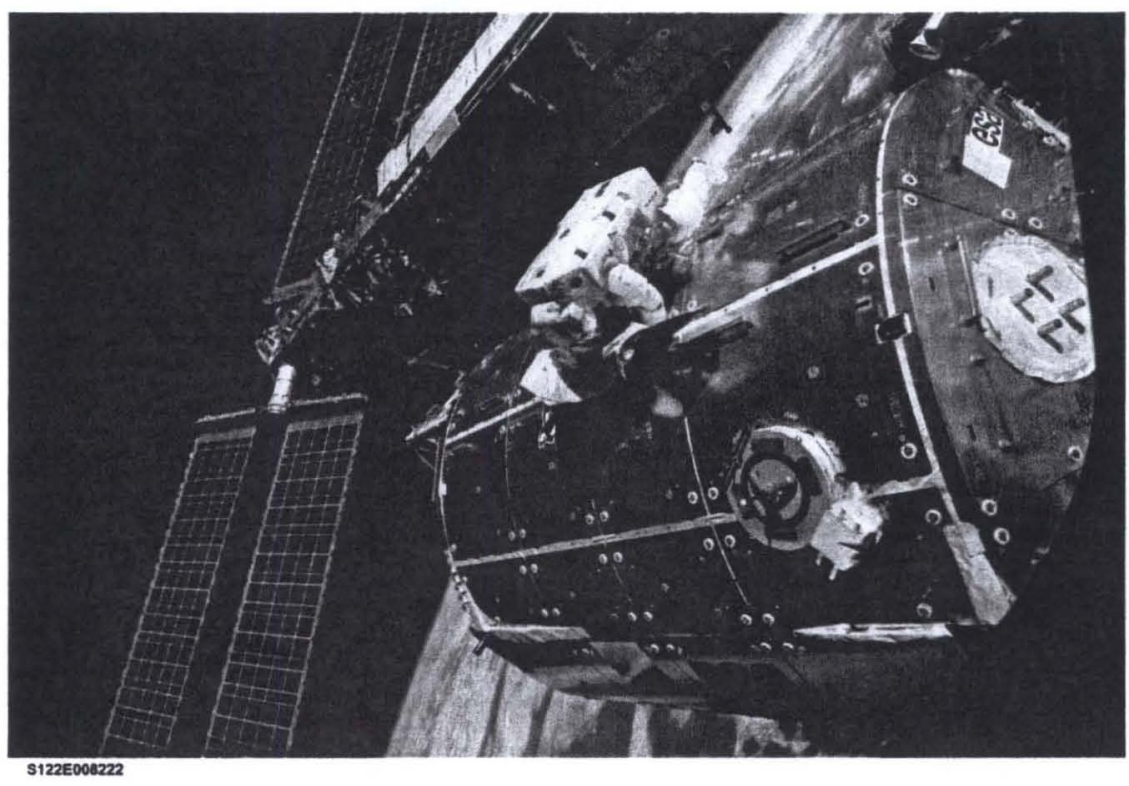

Fig. 2. STS-122 delivered Europe's Columbus Laboratory to the Station in 2007.

To move forward as a progressive civilization, new systems are needed that will allow astronauts to once again travel beyond Earth orbit to destinations that promise to yield new resources and reveal knowledge that will ultimately rewrite science textbooks and spawn new technologies with Earth-based applications. And these systems must substantially reduce operations costs to sustain the multi-decade program (fig. 3) enabled by the development of the first new U.S. human-capable space transportation infrastructure in over 30 years. Ultimately, this capability will allow international partners to strike out for new frontiers and realize the profit that comes from a robust, longterm commitment to mutually beneficial discovery, as documented in the Global Exploration Strategy. ${ }^{1}$

Through the ages, transportation has been the key to opening new trade routes and delivering increased opportunities in many realms. Whereas the Shuttle was founded on the outstanding legacy of NASA's Apollo Program and Saturn V rocket that first carried astronauts to the Moon and back in the 1960s, the evolutionary space architecture being designed, developed, tested, and evaluated by the Constellation Program today builds on proven hardware from both Saturn and the Shuttle (fig. 4), as documented in NASA's Exploration Systems Architecture Study. ${ }^{2,3}$

While the current U.S. human-rated space transportation system has served with distinction for well over 2 decades, it requires labor-intensive work and is costly to operate in proportion to NASA's overall budget. Following the tragic loss of the Space Shuttle Columbia and crewmembers in 2003, the Columbia Accident Investigation Board's (CAIB's) report released later that year provided a comprehensive failure investigation and concluded that the aging Shuttle should undergo a major recertification if it were to continue flying. The CAIB also observed that the enormous task of human space exploration must have an overarching purpose that delivers benefits comparable to the risks inherent in such a complex endeavor. ${ }^{4}$ 
NASA's Exploration Roadmap

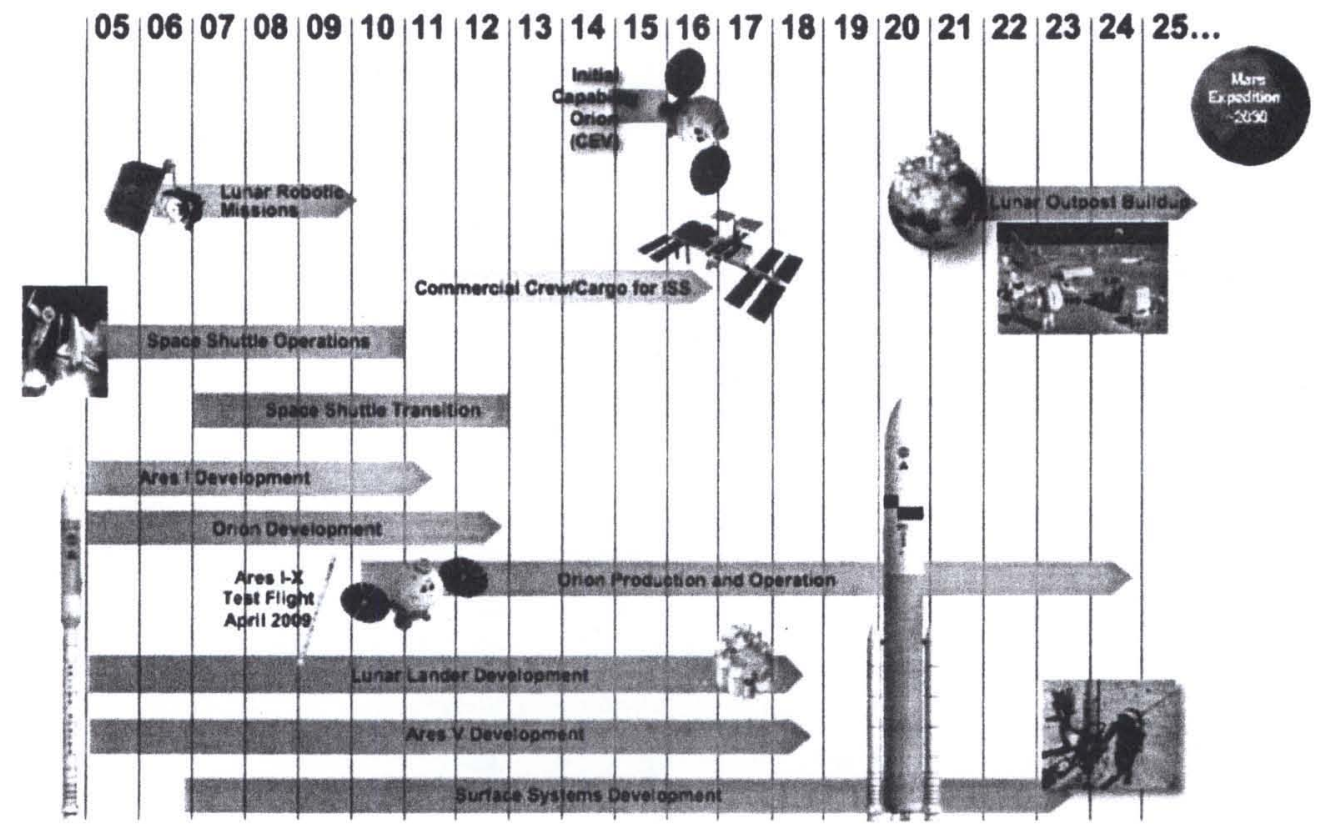

Fig. 3. The U.S. exploration timeline and architectural elements.
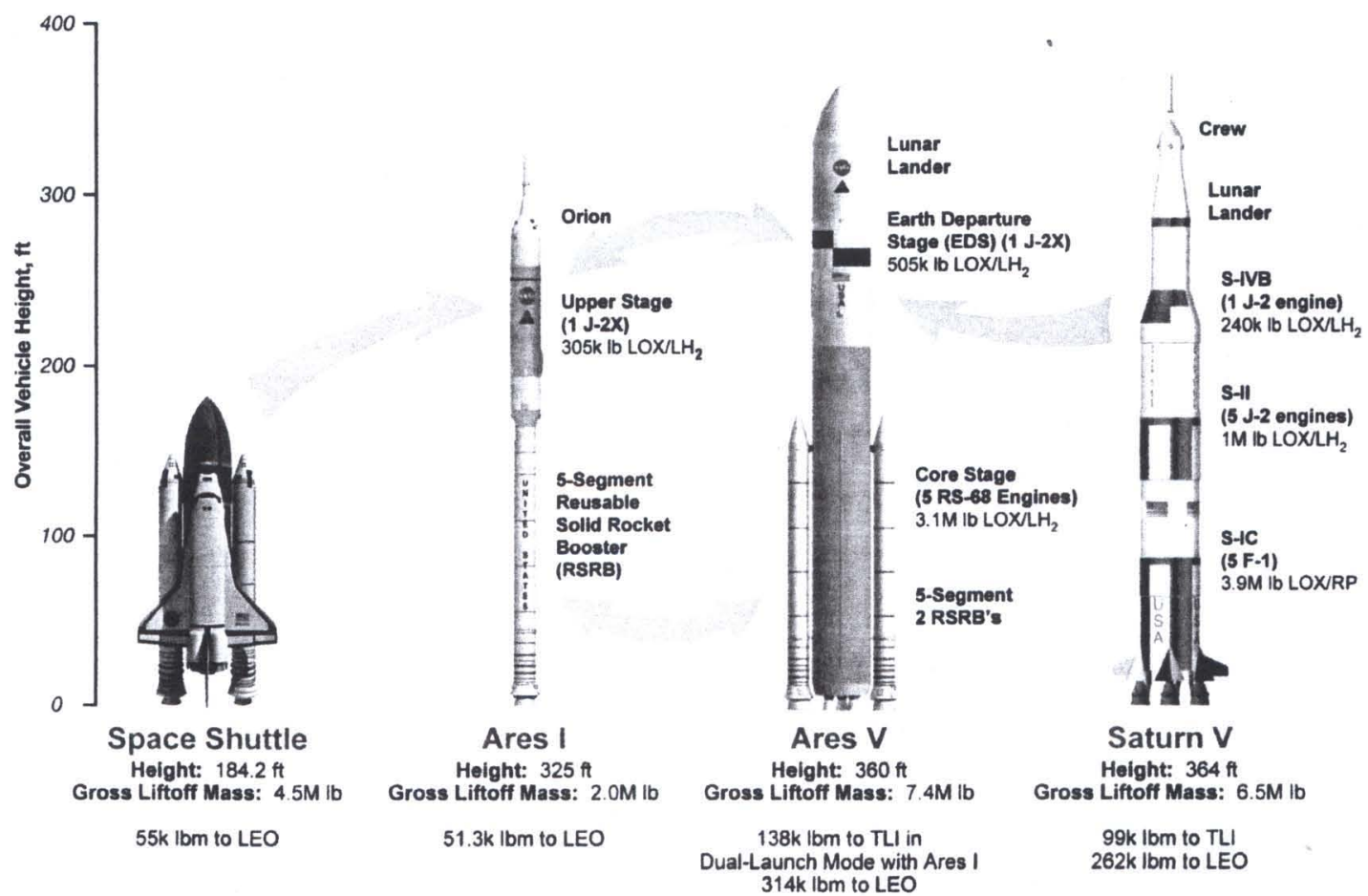

Fig. 4. Comparison of the Shuttle and Saturn V to the Ares I and Ares V. 
Subsequently, the U.S. Space Exploration Policy was enacted in early 2004, was authorized into law by the U.S. Congress in 2005, and is articulated in NASA's 2006 Strategic Plan. 5,6 The goals for America's investments in the space arena are to:

1. Fly the Shuttle as safely as possible until its retirement, not later than 2010.

2. Complete the International Space Station in a manner consistent with NASA's International Partner commitments and the needs of human exploration.

3. Develop a balanced overall program of science, exploration, and aeronautics consistent with the redirection of the human spaceflight program to focus on exploration.

4. Bring a new Crew Exploration Vehicle into service as soon as possible after Shuttle retirement.

5. Encourage the pursuit of appropriate partnerships with the emerging commercial space sector.

6. Establish a lunar return program having the maximum possible utility for later missions to Mars and other destinations.

When the Shuttle was returned to flight in 2005, it was with the expectation of retiring the system in 2010 and replacing it with a safe, reliable, and affordable next-generation architecture for the next step in the exploration of space by astronauts. Also in 2005, the Exploration Systems Architecture Study analyzed virtually hundreds of expendable launch vehicle and reusable launch vehicle systems and combinations relative to design reference missions to the Station, Moon, and Mars. Using volumes of previous studies and actual launch vehicle reliability and cost data, this expert panel comprised of engineering and business professionals concluded that separating crew from cargo could greatly improve the margin of safety.

As stated in the Exploration Study, the point of departure architecture recommended in mid 2005 provided a starting point from which engineering trade studies would be conducted, using safety, reliability, cost, and schedule drivers, to improve upon the initial concepts. Subsequently, using non-recurring and fixed lifecycle costs as independent variables in the methodology applied, the launch vehicle concepts were systematically refined to maximize system commonality and were baselined in March 2006.

For example, instead of using a modified 4-segment Shuttle-derived reusable solid rocket booster (RSRB) as the first stage for the Ares I and then developing a 5-segment reusable solid rocket motor (RSRMV) for the Ares V, the decision was made to go straight to the 5-segment version, saving on development costs and netting performance gains in the process. And instead of employing a reusable Space Shuttle Main Engine (RS-25) modified to start at altitude to power the Ares I upper stage and then developing the Apollo/Saturn-derived J-2X engine for the Ares V Earth departure stage (EDS), NASA decided to develop only one J-2X engine for both launch vehicle applications. This reduction from four major propulsion developments to two promises a major savings impact of billions of dollars. Such hardware commonality decisions affect the operations arena not only in terms of logistics, ground support equipment (GSE), and launch pad and processing procedures, it promotes economies of scale in hardware production.

While the first stage and upper stage engine selections have been matured along with the integrated vehicle configuration through several design analysis cycles, specific lunar plans are now coming to the forefront. Currently, the Ares V is slated to launch first and loiter on orbit for days or weeks while awaiting arrival of the Orion's crew (fig. 5). However, given technological and operational considerations, it is possible that the crew will launch first on the Ares I followed by the Ares V with its Earth departure stage transporting the Altair Lunar Surface Access Module (LSAM). In this lunar mission scenario, the Orion capsule will rendezvous with Altair in LEO before the J$2 \mathrm{X}$ engine fires for trans-lunar injection and the LSAM performs the lunar orbit injection (LOI). However, putting the crew in orbit first, followed by the cargo, may reduce costs and positively impact operations, as well. 


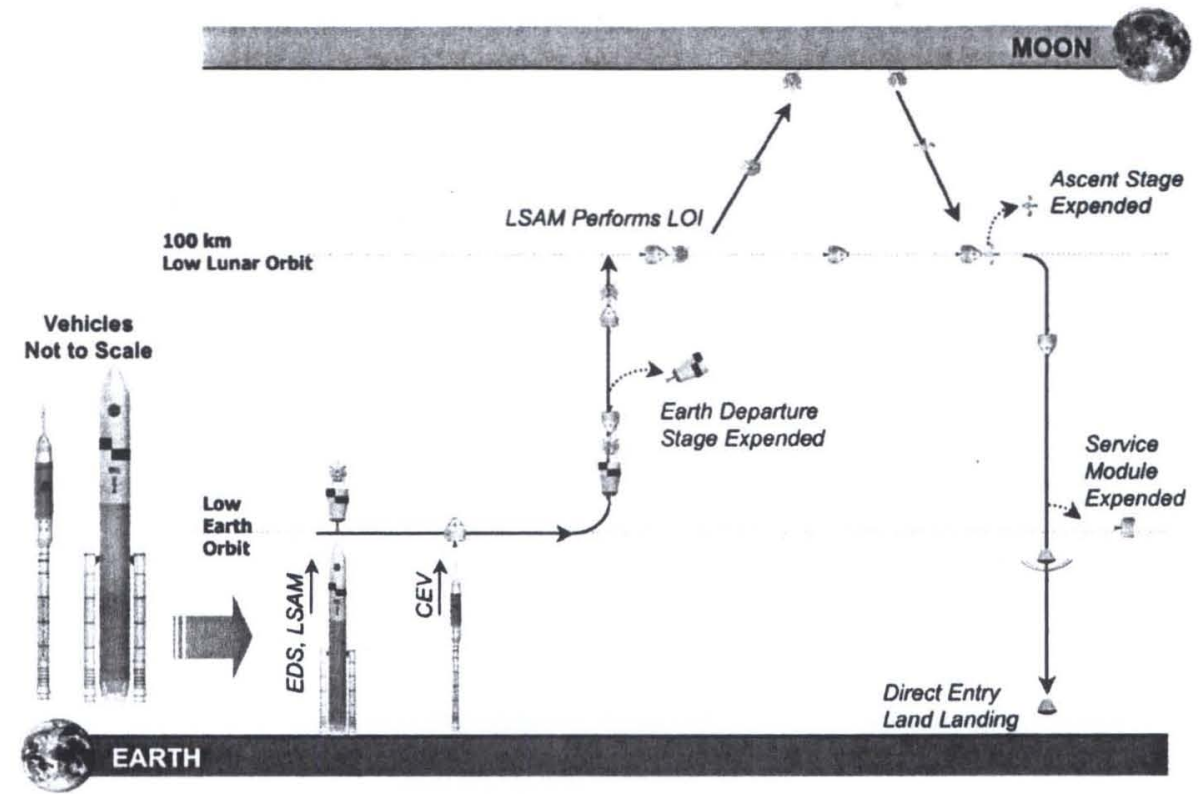

Fig. 5. Lunar mission scenario.

For reference, the current Ares I concept, shown in fig. 6, is a two-stage in-line configuration that places the Orion on top of the integrated stack. The Launch Abort System on top of the capsule is designed to quickly move the crew away in case of a launch emergency. As stated above, the Agency's hardware approach is to build upon the existing technology knowledge base to the maximum extent possible - the Ares I first stage 5-segment RSRMV is evolved from the 4-segment RSRB used on the Shuttle today, and the in-house designed upper stage will be powered by a J-2X upper stage engine, an evolution of that used on the Saturn V upper stages. The RSRB and J-2X will be extensible to the Ares V, with the addition of a cluster of modified off-the-shelf core stage engines: the RS68 now in the Delta IV evolved expendable launch vehicle (EELV) inventory. Again, this hardware commonality with the Ares $\mathrm{V}$ is a development approach that is expected to reduce both nonrecurring and recurring costs.

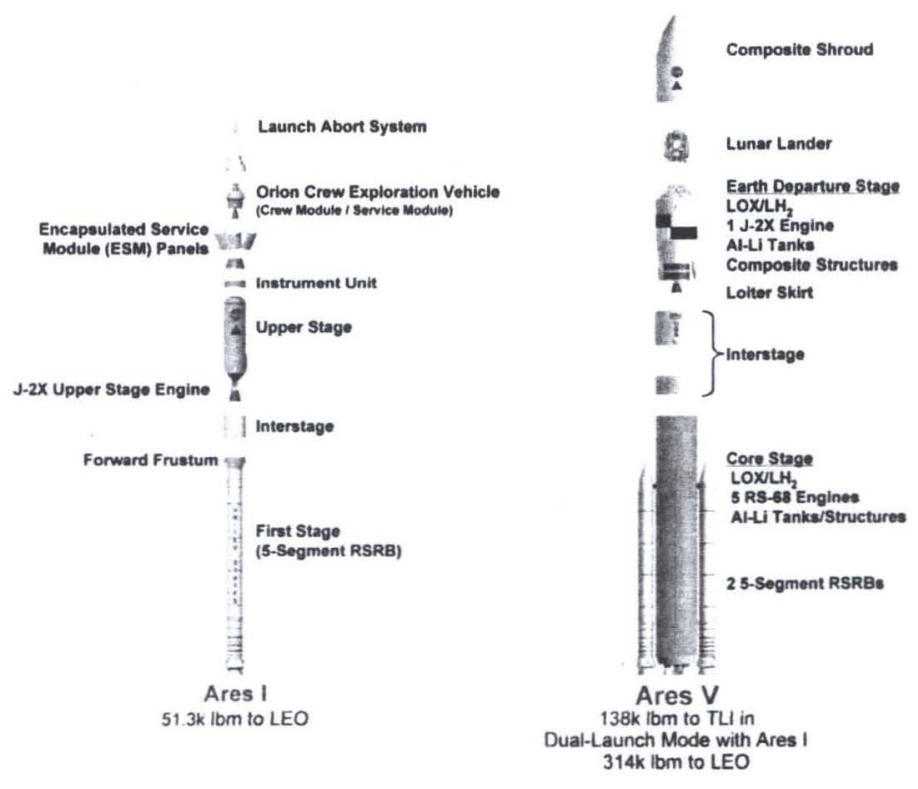

Fig. 6. Expanded views of the Ares I and the Ares $V$.

American Institute of Aeronautics and Astronautics 
The Ares I vehicle system designers also are planning for operations efficiencies through various approaches, such as utilizing modern modeling and simulation tools that deliver a level of understanding of the interaction of the parts of a system, and of a system as a whole. These results are anchored in three dimensions through a number of avenues, such as wind tunnel testing, hardware mockups for spatial fit-checks, and early flight testing in real-world environments, as outlined below. Decisions based on data such as these early in the development process reflect the design for operability philosophy put into place at NASA to ensure that quality systems are delivered on time and within budget, both in the near term and the long run.

\section{Investing in Space Operations}

First-hand lessons have taught us that to put productive space exploration on sound footing requires that efficiencies be designed into the transportation system and implemented in the development stage. Applying experience gained through decades of ground and space operations, while using value-added processes and modern business and engineering tools, is the foundation upon which a new era of exploration is being built to solve some of the most pressing exploration challenges today - safety, reliability, and affordability.

Currently, NASA is appropriated around $\$ 17$ billion annually, which is less than 1 percent of the overall U.S. Federal budget. NASA's Fiscal Year 2009 (FY09) budget request includes $\$ 3$ billion for Shuttle operations, or about 18 percent of its total budget. ${ }^{7}$ The Constellation Program's affordability requirement is for the next space transportation system to reduce this expense by more than 50 percent.

To broaden this frame of reference, NASA's FY09 budget request also includes $\$ 2$ billion for developing the Orion crew capsule and Ares I launch vehicle. In 2007, actual expenditures on space operations, including science and human missions, were $\$ 6.1$ billion; projections for 2008 are $\$ 6.7$ billion, and for 2009 are $\$ 5.7$ billion. Savings made in these areas will allow NASA to invest more in space-based scientific operations.

NASA Marshall Space Flight Center's Engineering Directorate provides solutions-oriented approaches to designing operations efficiencies into the Ares launch vehicles, including training, conducting, and implementing Lean/Six Sigma practices, as well as providing planning for streamlined hardware testing, integration, and logistics processes, such as assembling and testing major hardware elements before shipping to Ground Operations at the Kennedy Space Center for vehicle stacking and launch.

The Engineering Directorate provides both the intellectual capital embodied in an experienced workforce and unique facilities in which to perform research and validate modern modeling and simulation techniques. This capability includes the information technology tools that allow a nationwide team to collaboratively connect across miles that separate them and the highly specialized disciplines that integrate various parts into elements, then into a complete system with an operational life estimated at 30 years.

As NASA transforms its ground-based testing, manufacturing, logistics, and operations infrastructure, it also is transitioning its workforce from an era of intense hands-on labor to one of mechanized conveniences and robust hardware with simpler interfaces. Engineering personnel have conducted industry best practice studies using the Ariane 5, Atlas V, and others, which show that streamlining manufacturing and reducing the operations footprint to more closely reflect that of expendable launch vehicles is a valid business model. While the Ares launch pad may never be as austere as the Atlas V pad unveiled in March 2008 at the Vandenberg Air Force Base in California, its structure will be vastly simpler than that of today, which evolved from the Saturn V launch pad of Apollo (fig. 7). Given below are top-level details for approaches to cost savings, including both process and product improvements, which will result in space transportation systems that have operations efficiencies as a driving requirement. ${ }^{8}$ 


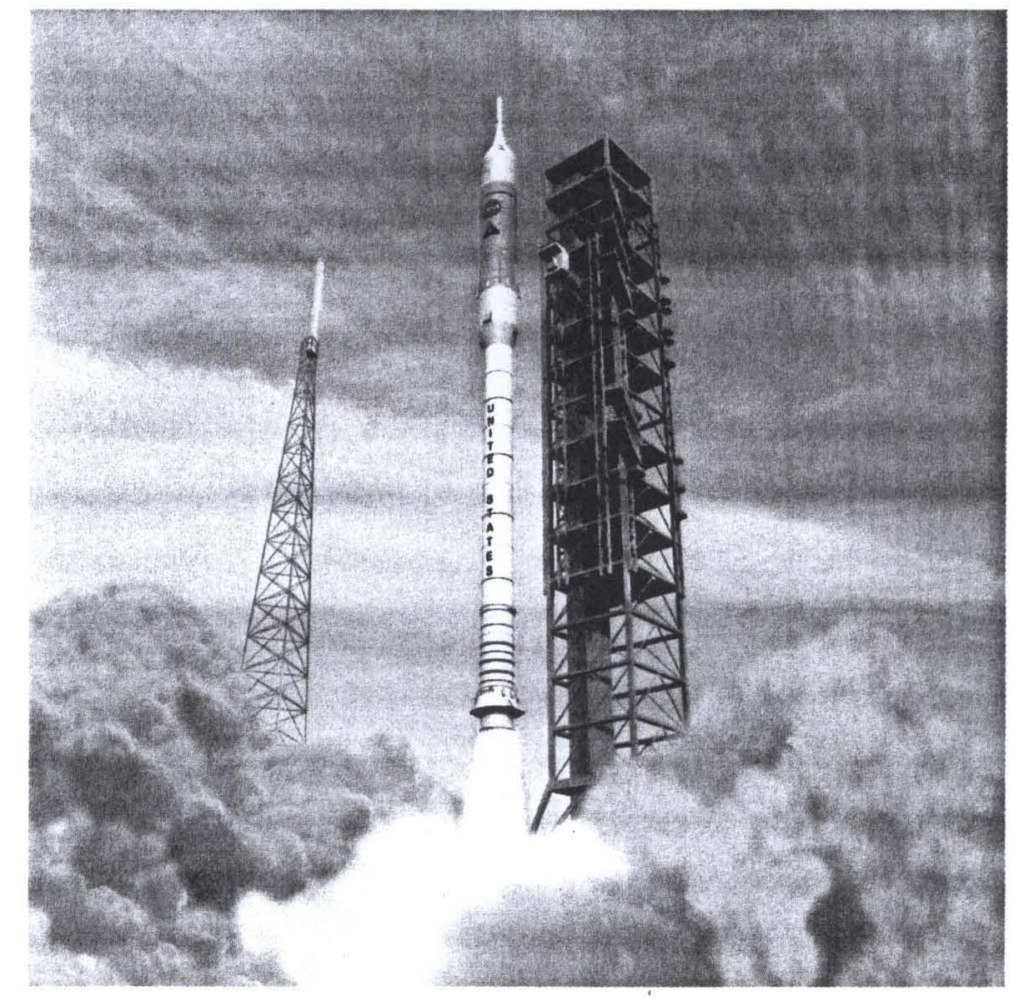

Fig. 7. NASA concept of the Ares I launch pad with lightning tower, which also will serve the Ares V.

\section{Designing for Operability}

Simply stated, the cost of access to space limits the budget that can be invested in the missions that space transportation enables. It has been estimated that 80 percent of operations costs are determined during the concept development phase; therefore, the Ares I design work is in the phase of highest leverage to affect significant change. ${ }^{9}$ With this knowledge as a foundation, given below are several examples of how operations efficiencies are being addressed early in the Ares I design process, which has completed several major systems engineering milestones, including the system requirement review in 2006, and the system definition review in $2007 .{ }^{10}$ As the new launch vehicle system approaches its preliminary design review, the importance of systems engineering and the design-for-operability discipline gain even greater attention and importance.

Operability is the combination of inherent design characteristics that determine both availability and affordability. Availability is the probability that a system or piece of equipment will operate satisfactorily at any point in time that it is required. Affordability is the determination that the system's lifecycle cost is in consonance with long-range investment and mission plans.

Factors that affect these two operability characteristics include safety, maintainability, reliability, supportability, and manufacturability. Safety is freedom from conditions that can cause injury or death to personnel, damage to or loss of equipment or property, or poses some hazard to the mission. Maintainability refers to how easily or quickly a system can be restored after scheduled and unscheduled interruption through failure or routine removal from service for maintenance. Reliability is the probability that a system or product will satisfactorily perform its intended function for a specified period of time under specified conditions. Supportability is the degree to which the system can be provided for, and manufacturability is how easily and economically a product can be produced. 
The business of delivering new space transportation capabilities includes operations concepts that reduce both recurring costs - such as propulsion element production, sustaining engineering, and processing the launch vehicle stack - and nonrecurring costs - such as modifying the existing launch infrastructure to accommodate these new systems. By studying the pros and cons of past and present launch vehicle manufacturing and processing, operability trade studies and recommendations are made as part of the design process. System operability metrics include such things as:

- Expendable Hardware Manufacturing and Consumables: Touch labor, direct material and other direct costs, and direct manufacturing support such as tooling, engineering, and maintenance, tool crib support, quality assurance, scheduling, and facility maintenance; includes solid propellants.

- Vehicle Spares: Replenishment of stock of flight hardware spares (line replaceable units); includes offline repair/replacement, logistics operations, and supplier skills retention for unique parts; excludes nonrecurring initial spares lay-in.

- Sustaining Engineering: Steady state engineering base required to ensure performance of preflight, mission, and post-flight analyses; anomaly resolution; engineering modifications; test support; etc., for each major flight hardware element at the subsystem level.

Creating appropriate handoffs from development engineering to operations functions is one of many decisions to be made relative to fielding a new space transportation system. As stated in NASA's Systems Engineering Handbook, "the successful transition of systems to operations and support, which includes maintenance and improvements, depends on clear transition criteria that the stakeholders agree on." In addition, "The transition to the operations and support phase represents a shift from the delivery of products to the delivery of services." As defined here, sustaining engineering is a service that must be consciously planned for, not conducted in an ad hoc fashion, and it must, in turn, be part of the long-range concept of operations. ${ }^{11}$

Marshall's Engineering team is integrally involved in technical oversight of the Ares first stage and upper stage engine and avionics. In a different business case, it is using in-house talent to design the upper stage and integrate the vehicle stack. ${ }^{12}$ Marshall's Huntsville Operations Support Center (HOSC), which is managed by the Engineering Directorate's Mission Operations Laboratory, has been integral to NASA's missions from the earliest days of U.S. spaceflight to current Station science operations. Planning for future missions beyond low-Earth orbit, Mission Operations Lab personnel serve on working groups and integrated product teams with the Mission Operations Directorate at the Johnson Space Center and with the Ground Operations Project at Kennedy.

With more than 7 years of continuous experience working with international crews on the Station and corresponding scientists on Earth, the Mission Operations Lab has the personnel, facilities, protocols, and distributed network in place to conduct orbital missions 24 hours a day/7 days a week in the Payload Operations Control Center (POCC) (fig. 8). This capability builds on decades of experience monitoring Shuttle propulsion elements during launch up to main engine cutoff and working with crewmembers to conduct real-time hands-on science missions in the 1970s, 1980s, and 1990s. Services include procedures and timeline development along with crew training, as well as coordinating payload activities for the Station's international partners, including the European Space Agency, Japanese Aerospace Exploration Agency, Canadian Space Agency, and Russian Space Agency. ${ }^{13}$

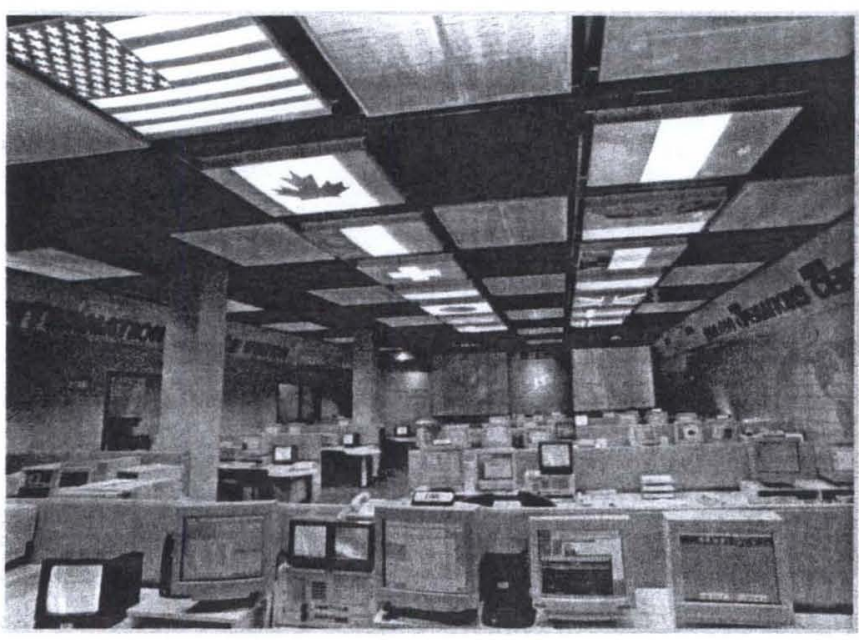

Fig. 8. Marshall's Payload Operations Control Center serves as a test bed for operational concepts. 
Affordability requirements drive innovative ways to reduce the new space transportation system's operational footprint across the board by building on the knowledge, experience, infrastructure, and resources resident in the Payload Operations Control Center, while providing the integration point for international scientific cooperation. The POCC is, in essence, a test-bed for both launch monitoring and sustaining engineering concepts, while offering the specialized data networks and protocols needed for science operations in Earth orbit and beyond.

\section{A. Concept of Operations}

This section provides a frame of reference for the interfaces across the Constellation Program's multiple projects and gives a top-level overview of the ground and flight operations requirements and goals, primarily to acquaint the reader with plans that are unfolding to reduce complexity and, by extension, costs. The Ares I Operational Concepts Document has been developed by Mission Operations Lab personnel in partnership with the Mission Operations Directorate and the Ground Operations Project to streamline processes for quicker vehicle turnaround and simpler interfaces for less hands-on labor. The launch vehicle design drives modifications to Kennedy's Vehicle Assembly Building (VAB) (fig. 9) and Launch Complex (LC) 39B, as well as requirements for manufacturing, shipping, stacking, launching, and operating.

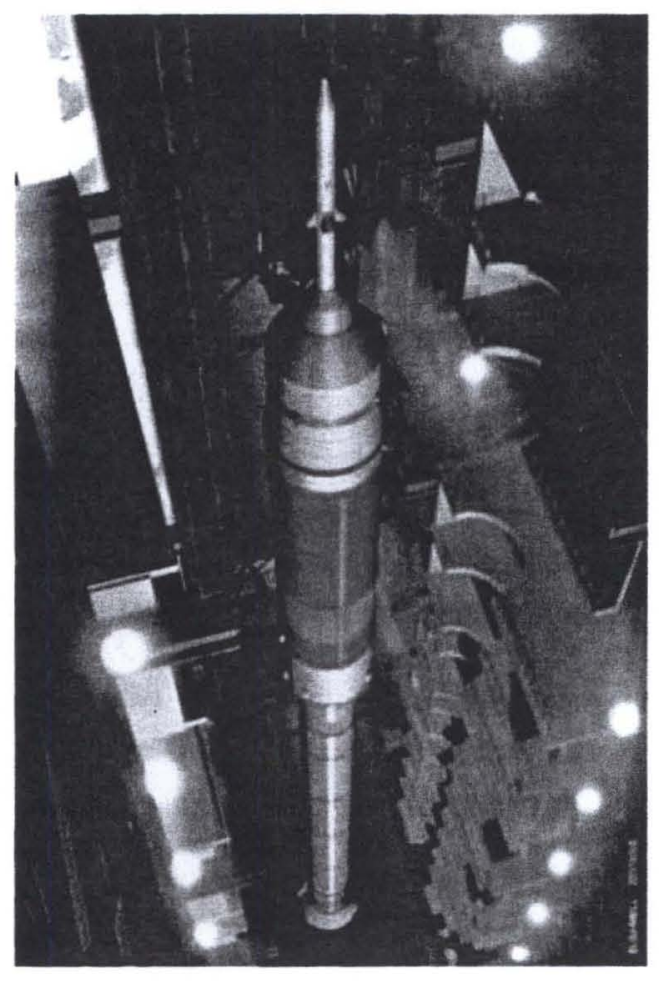

Fig. 9. NASA concept of the Ares I in the Vehicle Assembly Building.

When performing analytical studies to improve the turnaround time for the new system, technical metrics are balanced with programmatic cost and schedule targets. As mentioned earlier, one outcome has been the decision to mate the J-2X engine in the upper stage for green-run testing before shipping to the launch site. Another innovation has been to develop a full-scale mockup of the Ares I upper stage instrument unit structure, which provides guidance and control and other avionics functions to the craft, and of the Ares I interstage, complete with low-fidelity engine mold line (fig. 10). This serves as a physical mockup for laying out components and testing ground support equipment concepts, translating them from two-dimensional computer aided models to three-dimensional structures. This simulator is being used by design engineers and operators to make decisions that ultimately will affect Ares lifecycle costs. 


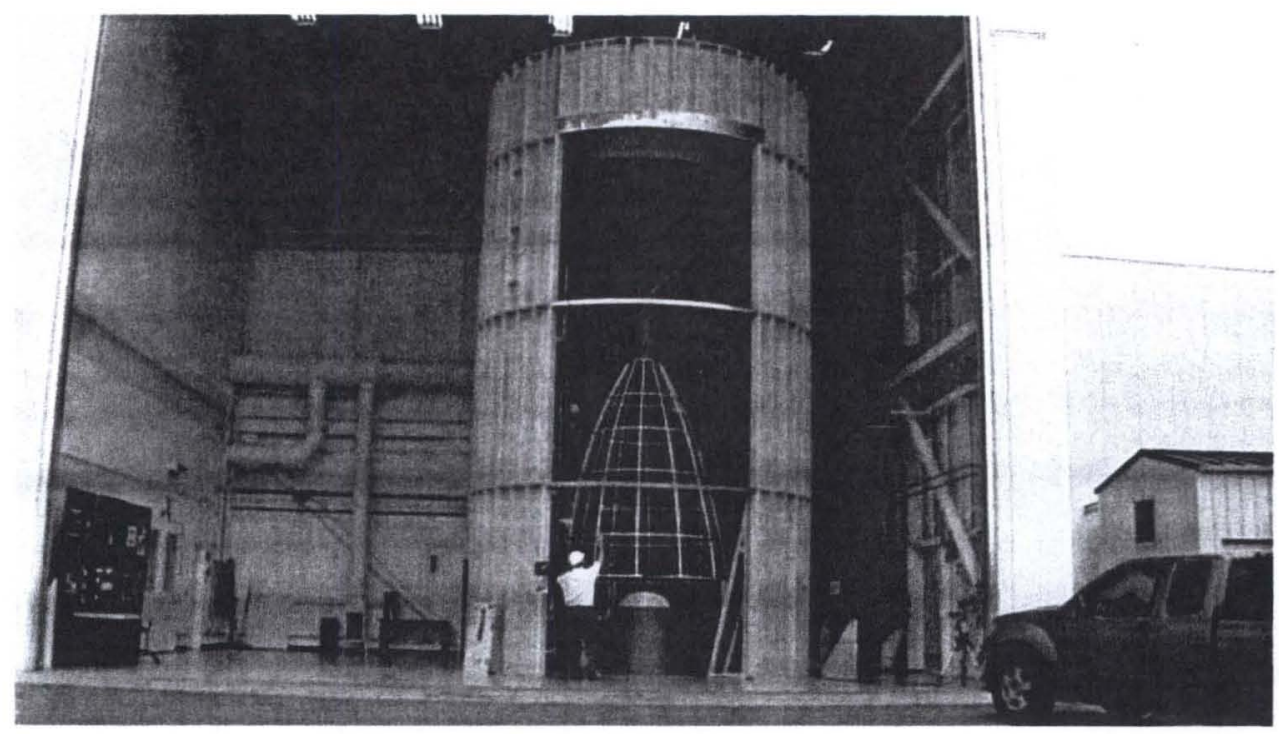

Fig. 10. The Ares I upper stage performance analysis design demonstrator.

For clarification, the Constellation Program consists of multiple systems that are all addressed by the Ares Operational Concept. These systems are grouped into four categories:

1. Crew Vehicles and Systems includes the Orion crew capsule, the Altair Lunar Lander, the Suit Systems for Extra-Vehicular Activities, and Flight Crew Equipment. In the future, the Mars Transfer Vehicle and the Mars Descent/Ascent Vehicle will be added to the active program.

2. Launch Vehicles and Systems include the Ares I for crew and the Ares V for cargo.

3. Ground and Mission Systems consists of the hardware and software systems.

4. Future Destination Surface Systems consists of the habitat, surface mobility, power, and robotic and resource utilization systems.

Ares I ground and flight operations concepts and goals are driven by the mission manifest; design reference missions; Constellation Program constraints; the Constellation Program's needs, goals, and objectives; and Ares I design decisions. Operations goals are established as targets for improving upon existing capabilities. The operations requirements are based on operations analyses and timelines, which include turnaround time, launch availability probability, and so forth.

The Ares I ground and flight operations goals are summarized below:

- Achieve a significant reduction in operations cost from legacy systems, with the goal to operate at a steadystate flight rate of 6 flights per year.

- Simplify and minimize ground processing and integration operations such that the system can be launched within $\mathbf{4 5}$ calendar days from the launch of the previous Ares I mission.

- Be interchangeable with either mission type (crew or cargo) such that no significant changes in processing flow or element hardware are required.

- Elements should arrive at the Kennedy Space Center without open factory work.

- Achieve the appropriate balance between the use of line replaceable units, reliable component selection, and maintenance operations to support a launch availability of not less than 98 percent (not including natural environmental impacts).

- Minimize launch pad processing time such that it is ready for launch within 7 days from the integrated system's arrival at the launch pad.

- Reduce, to the maximum extent practical, any launch pad maintenance during the 4-day launch window.

- Be capable of a 24-hour turnaround following a launch scrub.

- Be capable of supporting the next trans-lunar injection (TLI) window following a missed launch attempt.

- Use common, reusable ground support equipment throughout pre-launch processing and launch operations.

- Incorporate common parts and tooling as much as practical.

- Be capable of remaining in a stacked configuration for up to 180 days.

- Minimize ground system diagnostic, maintenance, and umbilical interfaces. 
- Implement a logistics support concept with the appropriate balance between just-in-time shipment, certification life, and hardware spares to minimize the launch site logistics footprint (storage facilities, equipment, and personnel) and to eliminate the need for on-site hardware recertification.

Scenarios described in the Ares I Operational Concepts document are based on the sequence of activities for each of the operational phases (fig. 11). These help determine launch vehicle segment and supporting systems capabilities, interfaces, and operational timelines. By methodically decomposing the steps that must occur at each operational phase, the Ares Engineering team has a better understanding of how to reduce complexity for efficient launch solutions. These and other variables are used as inputs for the design-for-operations approach, which is summarized below.

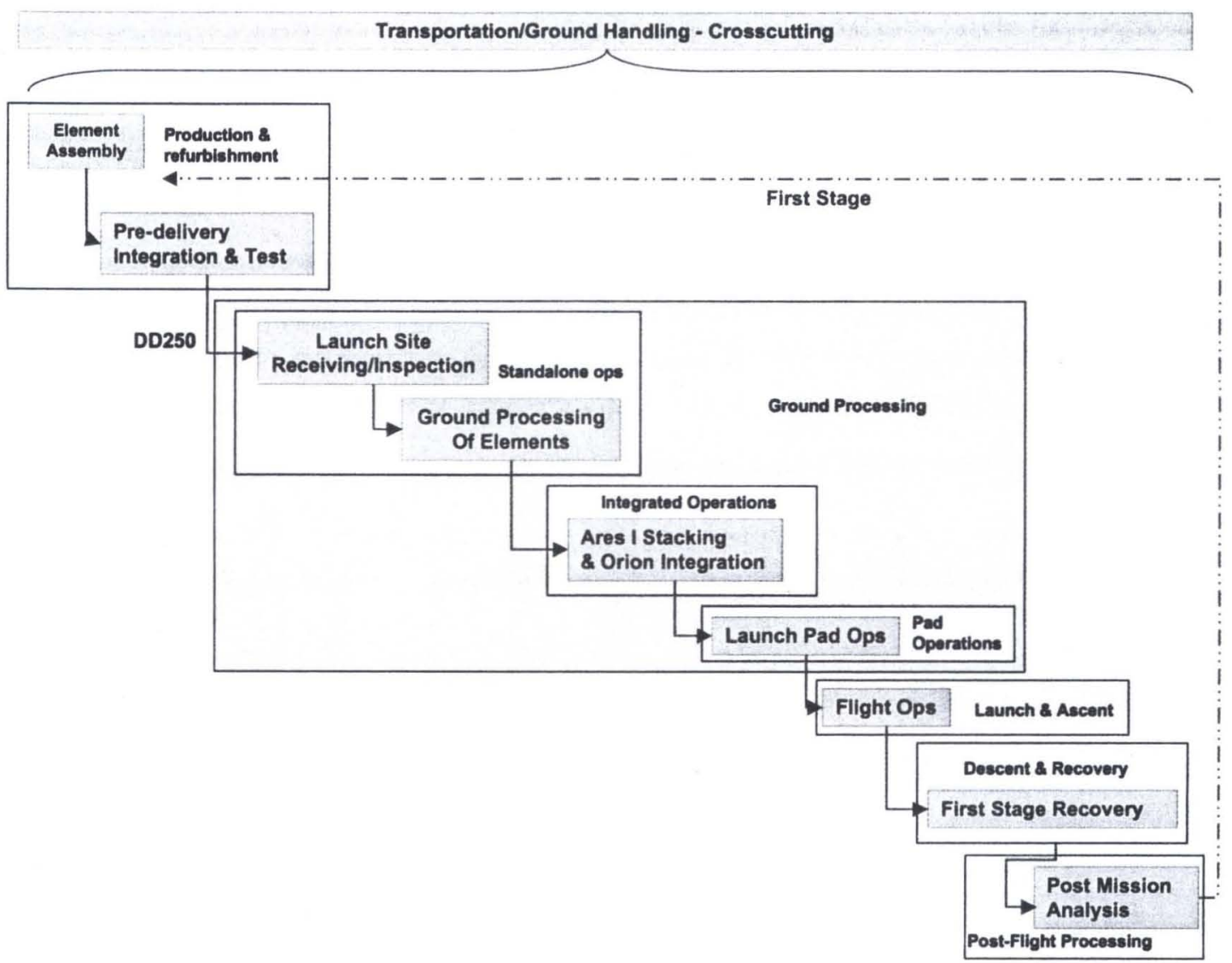

Fig. 11. Ares I operational phases.

\section{B. Operations and Supportability}

An Ares operations manager and various working groups and integrated product teams focus on simplifying factors that drive launch costs. The design-for-operations objective is to reduce system support costs, both hardware and non-hardware, by performing trade studies that analyze recurring and non-recurring costs. In this way, operations expenditures must "buy" their way into the mission concept.

As defined here, operations and supportability factors include manufacturing, logistics, transportation, flight processing, engineering and project support, and refurbishment activities. The design-for-operations roadmap is a three-step process involving: (1) requirements, (2) design, and (3) manufacturing and site operations. The first step is to understand operations cost drivers, including Shuttle operations and infrastructure and expendable launch vehicles performance as data points. The second step is to ensure that requirements are addressed and aggressively managed during the design process through activities such as personnel training to create a culture that is accountable for operability, allocating requirements to system elements (including system responsibility for operational costs), and designing for manufacturing and operations. Progress toward these requirements is tracked 
through Engineering management reviews and at targeted opportunities such as quarterly operations management reviews. The third step involves utilizing Lean/Six Sigma techniques and other such processes to improve quality, while simultaneously reducing cycle time and associated costs by eliminating waste and non-value-added activities. This approach is aimed at minimizing defects in workmanship throughout the range of operations activities, as well as maximizing resource utilization. Another innovation that contributes to accuracy through configuration control is the Distributed Data Management System that is being implemented across the Engineering disciplines that contribute to this design work.

Within the Ares work breakdown structure is an Operations and Supportability function that is currently focused on the vehicle's ability to meet operations requirements; development of the Operability Assessment Report; and development of the Sustaining Engineering Concept. Comprehensive documents that supplement and support the Operations Concept described above include the Ares I Ground Operations Data Book, the Ares I Preferred Common Parts Selection Document, the Ares I Ground Support Equipment Plan, and the Ares I Integrated Mission Timeline, to name a few.

This functional area addresses seven top-level driving requirements:

1. Critical path applications for ground launch: Stack and integration time, ready for integrated testing, powered testing, finish testing-to-pad connection, and pad connection complete to launch.

2. Launch interval: Back-to-back launches in $\mathbf{4 5}$ days.

3. System readiness from start of stacking to call to stations: System readiness not less than 85 percent, with confidence level of 95 percent.

4. Probability of launch, excluding weather factors: Beginning with decision to load cryogenic propellants and ending with the closing of the day-of-launch window with first attempt.

5. System maintainability: Recovery times for various scrubbed launch causes.

6. Consecutive launch attempts for lunar missions: No less than seven consecutive days.

7. Recurring cost: Vehicle integration maximum threshold production cost.

In working toward a streamlined timeline, critical path segments include the:

- Mobile Launch Pad refurbishment

- Vehicle Assembly Building preparations

- First stage stacking

- Upper stage/upper stage engine installation

- Orion/launch abort system installation

- Orion/Ares integrated test and closeouts

- Ares I Pad operations

By quantifying the cycle time for each of these activities, on-line cycle time for critical path segments can be measured against requirement targets. Not included in time estimates are administrative or logistics delays, rootcause failure analysis, removal and reinstallation of the safe-and-arm features, or system recertification for flight.

The operability assessment process includes five comprehensive steps that, combined, give the first systematic evaluation of Ares I operability. Assessing the design includes evaluating elements to the subsystem level, collecting inputs from subject matter experts, using existing design data, and assigning predefined ratings. Evaluating operability includes identifying operability gaps and comparing various designs. Investigating causes includes tracing low-operability areas down to the subsystem level, investigating the cause to determine lack of functionality, and generating related action plans. Tracking progress involves capturing and monitoring all issues and action items, tracking concerns through design changes, and evaluating/analyzing the vehicle design to assess the results. Finally, findings are presented to the Ares Standing Review Board and close-outs are initiated within the lessons learned database.

Mission Operations Laboratory personnel developed an operability punch list to serve as a forcing function to implement design attributes that affect the program, yet which are not explicitly identified by specific requirements. This tool helped drive engineers toward optimized design solutions that consider performance, availability, safety, reliability, affordability, and operability specifications. The punch-list process allows items to be added that may become operability issues, resolutions tracked, and closure rationale documented. This tool has successfully created situational awareness of element, project, and program progress toward a balanced, sustainable system.

Each Ares I element (first stage, upper stage, upper stage engine, and integrated vehicle) has a core operations working group and is ultimately responsible for a design that fits squarely within the operations requirements levied on the system. The Ares I upper stage is a clean-sheet element that is being designed and developed in house at the Marshall Center. The implementation plan includes transitioning the design to industry for production at NASA's Michoud Assembly Facility (MAF), where the Shuttle's external tanks currently are produced and where the Saturn 
$\mathrm{V}$ tanks were made. The prime contractor selected for this task has demonstrated Lean/Six Sigma capabilities in aerospace production, offering the potential to significantly reduce manufacturing time, saving valuable resources.

Although a brand new upper stage subsystem inherently carries more risk than modifying an existing structure, this approach has many advantages, including designing for increased reliability to meet human-rating requirements and to allow extensibility from the crew vehicle to the cargo vehicle. A new design also promotes use of state-ofthe-art materials, hardware, and design, fabrication, and testing techniques and processes, which are being developed and evaluated in the Engineering Directorate's Materials and Processes Laboratory. This Engineering team will build two upper stage structural test articles using aluminum-lithium joined with friction-stir welding on one of the largest such manufacturing tools in the United States. In this way, by using primarily existing materials, techniques, and infrastructure, non-recurring and recurring costs can be reduced.

This 84-foot (25.6 meters) long and 18-foot (5.48 meters) diameter self-supporting cylindrical structure holds the fuel and oxidizer tanks. It is powered by a single J-2X liquid oxygen/liquid hydrogen (LOX/LH2) engine and consists of the following primary products:

- Instrument Unit (IU)

- Liquid Hydrogen Tank

- Common Bulkhead

- Liquid Oxygen Tank

- Aft Skirt

- Thrust Cone

- Main Propulsion System (MPS)

- Interstage

- System Tunnel

- Ullage Settling Motors

- Booster Deceleration Motors

- First Stage and Upper Stage Reaction Control System (RCS)

- Thrust Vector Control (TVC)

Keys to this effort are development of manufacturing and testing capabilities, as well as logistics and operations. For example, an integrated logistics analysis was implemented early in the design phase to ensure that the resulting hardware is optimized for safety and low-cost processing. This includes such things as facilities, transportation, and ground support equipment.

Upper stage testing, including the main propulsion test article and structural modal and vibration testing, will be conducted in government-owned facilities, including the Marshall Center and Stennis Space Center's (SSC's) test stands, which were used in the design and development of the Saturn V and the Shuttle. The Ares I upper stage element provides a case in point for streamlining not only processing and on-pad activities, it is an example of using lean manufacturing process flows to dramatically reduce recurring costs. Its traffic model includes manufacturing at NASA's Michoud Assembly Facility in New Orleans, Louisiana, with handoff from Michoud to Stennis in Mississippi for mating with the J-2X upper stage engine and acceptance testing prior to shipping to Kennedy for launch processing and mission operations.

Fig. 12 provides a top-level look at the upper stage processing, logistics, and ground operations segments. Upper stage operations and logistics activities performed by Mission Operations Lab personnel include the analysis and products to specify processes, requirements, and verification of the design, development, integration, and acquisition of the infrastructure for ground operations, flight operations, and logistics support to meet recurring operations cost and availability goals. This work area also establishes and provides sustaining engineering for upper stage operations and logistics. Supporting documents provided include the Michoud Assembly Facility Test Control Room Operations Concept and the Upper Stage Assembly and Integration Plan; the Upper Stage Ground Operations Concept Document, Ground Operations Plan, and Ground Process Flows; and the Flight Operations Requirements Document, Operations Data Handbook, Flight Rules Guidelines and Constrains, Launch Commit Criteria, and Sustaining Engineering Requirements/Plan. These and other products and services support the design and development of an upper stage that reflects government and industry best practices, an extensive knowledge base, and design-for-operability engineering. 


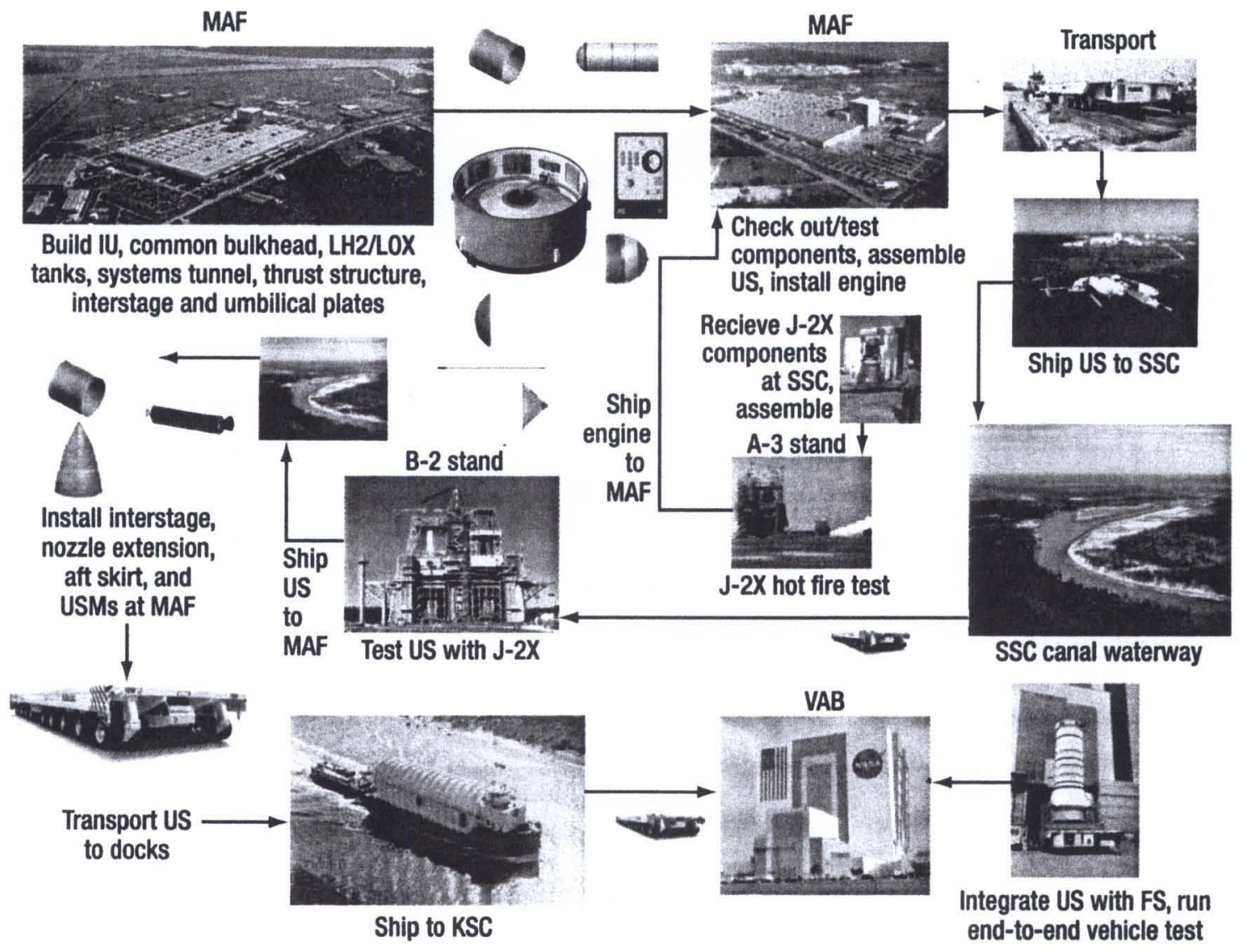

Fig. 12. Ares I upper stage manufacturing, logistics, and launch processing concept.

In addition, the Engineering team has conducted multiple product development Kaizen events, with the goal of reducing the flow time for items such as the upper stage common bulkhead honeycomb core and adhesive selection from 100 days to 65 days. Eventually, design activities such as these will culminate in an expression of the "test as you fly, and fly as you test" tenet. The Engineering team draws on analysis results from a variety of sources, including subscale wind tunnel models and from computer aided design applications that test integrated avionics software and simulate vehicle dynamics in cyberspace, leading to real-world testing with increasingly flight-like hardware to gain confidence in the system before orbital tests that will yield even more information on which to base critical hardware decisions related to long-term, sustainable flight operations.

\section{Flight Testing Strategy Also Tests Operations Concepts}

The Ares I-X suborbital development flight test slated for spring 2009, will encompass designing and developing a complete system, including a full-scale Flight Test Vehicle (FTV) and associated launch operations. The FTV comprises multiple elements (fig. 13), which are being developed at various NASA Centers and contractor locations. The elements and components will be delivered to Kennedy for assembly into an integrated, flight-ready FTV. Once the FTV is integrated and final checks are completed in the Vehicle Assembly Building and at the launch pad, the FTV will be launched on a suborbital trajectory. This process will test operations concepts, as well as support several high-priority technical objectives. Information gained will benefit the Ares I critical design review. 


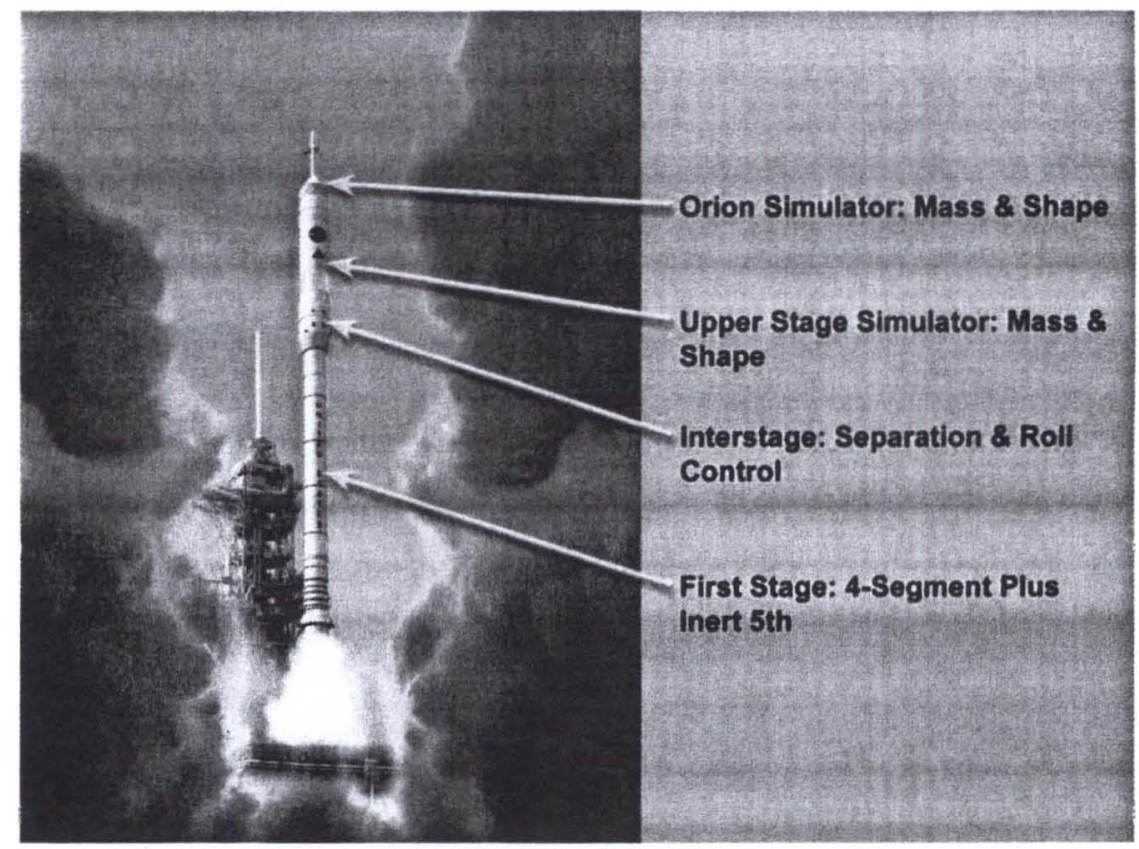

Figure 13. The Ares I-X flight test is planned for April 2009.

The primary objectives of this first flight test are to:

- Demonstrate control of a dynamically similar integrated Ares/Orion, using Ares ascent control algorithms.

- Perform an in-flight separation/staging event between an Ares I-similar first stage and a representative upper stage.

- Demonstrate assembly and recovery of a new Ares-like first stage element.

- Demonstrate first stage separation sequencing, and quantify first stage atmospheric entry dynamics and parachute performance.

- Characterize the magnitude of the integrated vehicle roll torque throughout the first stage flight.

During this developmental flight test, data will be collected by on-board vehicle sensors such as accelerometers, and from ground systems such as cameras. Critical data will be telemetered to the ground and all data will be recorded on board the vehicle. The on-board data recorder will be retrieved from the first stage after recovery. These data will be processed in accordance with the flight test objectives.

NASA plans to fly the Ares/Orion space vehicles with an improved margin of safety over - but also at a lower cost than - current Shuttle missions. These two requirements result in often-conflicting operational and philosophical approaches. Disciplines like Lean/Six Sigma call for fewer and more efficient steps, while Safety and Mission Assurance processes call for additional checks and balances to ensure the safety of astronauts and the vehicle, as well as people and property on the ground. One activity that raised this philosophical difference early on is the certificate of flight test readiness (CoFTR) process, which is the final approval of the system for flight.

In December 2007, the Ares I-X CoFTR process was reviewed and modified by managers from across NASA, using comprehensive value stream mapping that addressed three primary topics: (1) risk acceptance philosophy, (2) decision and approval authority, and (3) systems engineering processes While flying without a crew, Ares I-X serves as test case for the Constellation Program's ability to implement lean processes safely and affordably.

As a result of this meeting, representatives from the Constellation Program, the Ares Projects Office, the Flight and Integrated Test Office, Safety and Mission Assurance, and others developed a revised, more streamlined process flow for certifying the Ares I-X vehicle for flight. To minimize decision and approval times, the Ares I-X Project reduced the number of independent review boards from ten to four. Such organizational changes are necessary if Ares I-X is going to react quickly and make its 2009 launch date. Lessons learned from this exercise will shape certifications for the operational Ares I. This is one example of the product and process improvements that are being made using Lean techniques. For example, value-stream mapping added over $\mathbf{4 0}$ days of margin to the Ares I-X schedule in terms of aft skirt processing, thermal protection system installation, developmental flight instrumentation, and inspections. 
The various high-technology tools and techniques that are applied in the laboratory and research environments are no substitute for hands-on experience; therefore, the Ares I-X flight test also will try out new ground procedures at the launch site. Among the activities are stabilizing the vehicle during rollout from the Vehicle Assembly Building; setting up electronic ground equipment; studying the operation of the Flight Termination System; and loading the reaction control system propellants. These and other operations objectives will be analyzed and quantified as an integral step on the path to delivering data before the Ares I critical design review in late 2009.

After this flight test is complete, attention will be placed getting ready for future test flights on the new Ares launch pad. For Ares I, operations concepts map to a revamped Launch Complex 39B. As Shuttle operations wind down, Launch Complex 39A will be modified for the Ares V (fig. 14). ${ }^{14}$ The launch control room is being redesigned from Apollo vintage, and the Vehicle Assembly Building is being reconfigured for new stacking scenarios. A crawler-transporter will be built to accommodate the single-stick design of the Ares I. Propellants will be loaded on the pad during countdown. Structural/mechanical interfaces and ground power and servicing umbilicals will be mated to the vehicle, along with stability and damping mechanisms, as well as a crew ingress and emergency egress ramp. Relatively simple interfaces and streamlined workflow will reduce the number of personnel needed to stack, process, and launch the Ares I and the Ares V, saving valuable resources - both time and money.

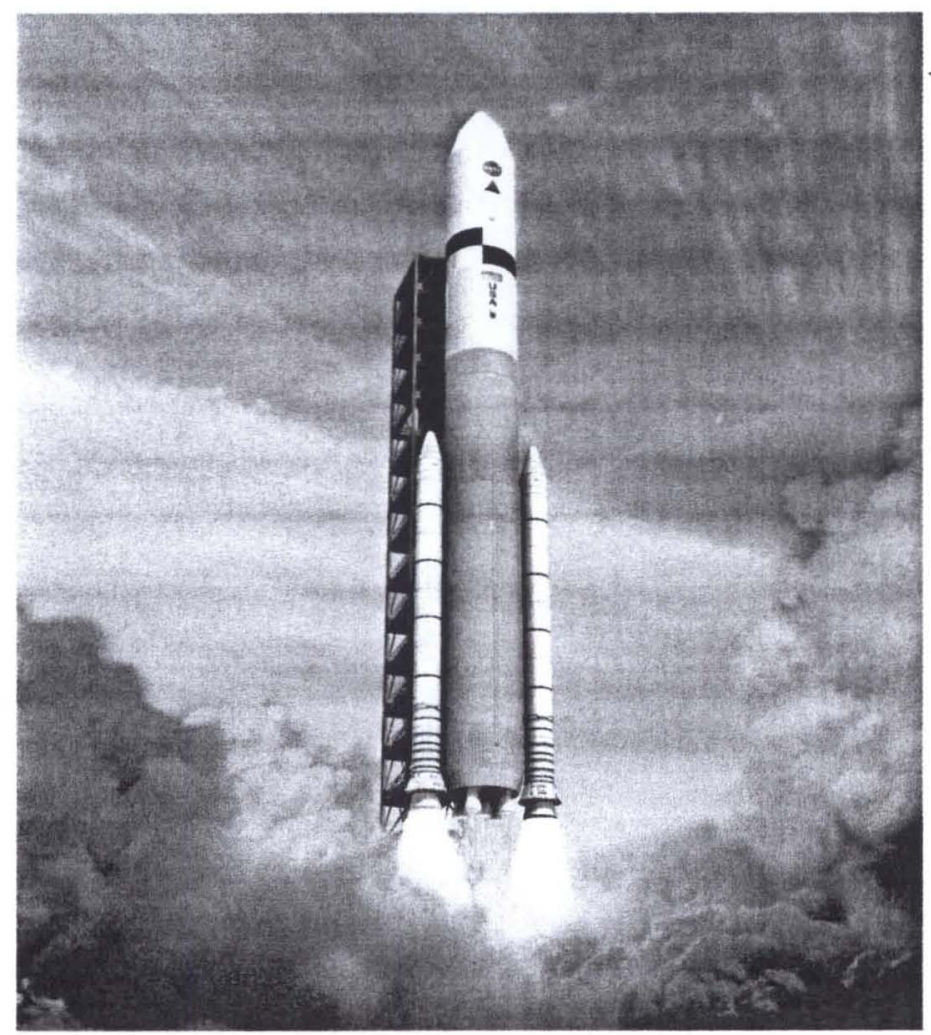

Fig. 14. NASA concept of the Ares V on Launch Pad 39A. 


\section{Conclusion}

Today's launch operations are complex, time-consuming, and require a great deal of hands-on labor, which are direct results of compromises made early in the Shuttle design phase. When the Ares I begins its operational phase in the 2015 timeframe, and the Ares V around 2020, they will be the culmination of a detailed systems engineering process that involves launch vehicle design engineers working in tandem with their operations counterparts to ensure that the system delivered meets requirements, goals, and objectives. Beginning with the end in mind reduces the risk of transforming and transitioning to the new space exploration architecture.

Mission success demands a disciplined, innovative approach to developing human space transportation systems that deliver safety and reliability, along with marked reductions in operations costs. This applies both to transitioning government space assets and to the forthcoming spaceports being developed by private industry for markets such as Station logistics and space tourism. ${ }^{15}$

NASA is applying rigorous systems engineering and management processes to ensure that technical performance is accurately reflected in, and inextricably connected to, budget allocations and schedule milestones. By building on a foundation of heritage knowledge and applying lessons learned from past and current missions, the probability of success is greatly increased. Persistent management of requirements "creep" will ensure that the new system is delivered on time and within budget. Focusing early and often on top risks and operations concepts in relation to performance parameters is vital to meeting U.S. exploration goals.

On the Moon, multi-cultural astronauts will gain the experience needed to travel to other worlds and learn to work productively, while relatively close to home (fig. 15). These lunar missions will serve as test-beds for technologies and survival practices that will enable the eventual first human trips to Mars - the planet most like Earth. While robotic spacecraft and rovers provide mapping data, scout potential landing sites, and locate in situ resources that can be utilized by the first Moon settlers and the inaugural explorers on Mars, NASA and its partners are engaged in the task of designing, developing, testing, fielding, and operating the space transportation systems that will carry a new generation of explorers on fresh journeys of imaginative discovery.

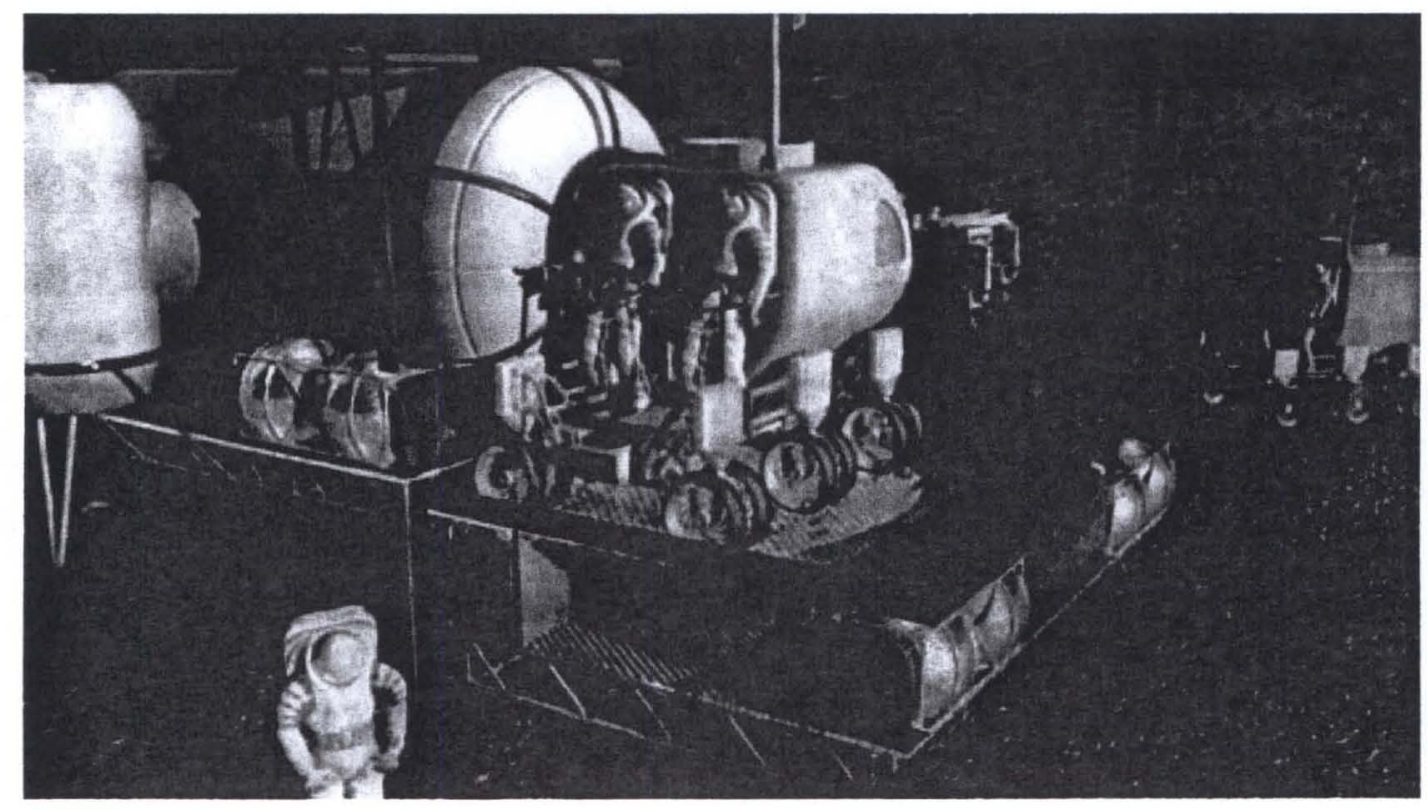

Fig. 15. NASA concept of lunar mission operations. 


\section{References}

1. Global Exploration Strategy: A Framework for Cooperation, May 2007, www.nasa.gov/home/hqnews/2007/may/HQ_07126_Exploration_Framework.html.

2. Heppenheimer, T.A., The Space Shuttle Decision: NASA's Search for a Reusable Space Vehicle, NASA Special Publication 4221, 1999.

3. Exploration Systems Architecture Study, Final Report, Technical Manual 2005-214062, November 2005, www.sti.nasa.gov.

4. Report of the Columbia Accident Investigation Board, August 26, 2003, www.nasa.gov/columbia/home/CAIB_Voll.html.

5. U.S. Space Exploration Policy, A Renewed Spirit of Discovery, January 2004, www.nasa.gov.

6. NASA Strategic Plan, 2006, www.nasa.gov.

7. NASA Fiscal Year 2009 Budget, www.nasa.gov.

8. Mecham, Michael, "Vandenberg's New Atlas V Pad," Aviation Week and Space Technology, February 11, 2008, p. 50.

9. Launch Vehicle Design Process: Characterization, Technical Integration, and Lessons Learned, NASA Technical Paper 2001-2100992, J.C. Blair, et al, p. 150.

10. "NASA Completes Review Milestone for Ares I Vehicle," January 4, 2007, NASA News, www.nasa.gov.

11. NASA Systems Engineering Handbook, Special Publication 6105, December 2007, p. 28.

12. "NASA Announces New Center Assignments for Moon Exploration," October 30, 2007, www.nasa.gov/home/hqnews/2007/oct/HQ_07234_ESMD_Work_Assignments.html.

13. Payload Operations Center Fact Sheet, March 2001, www.nasa.gov/centers/marshall/news/background/facts/POC.html

14. Jones, Thomas D., "Shuttle to Orion: First steps back to orbit," Aerospace America, American Institute of Aeronautics and Astronautics (AIAA), October 2007, page 28.

15. Douglas, J. Paul, "Space operations and support," Aerospace America, AIAA, December 2007, p. 92. 
NASA's Ares I and Ares V Launch Vehicles

Effective Space Operations Throuigh Efficient Grounsd Opperel ij cyes

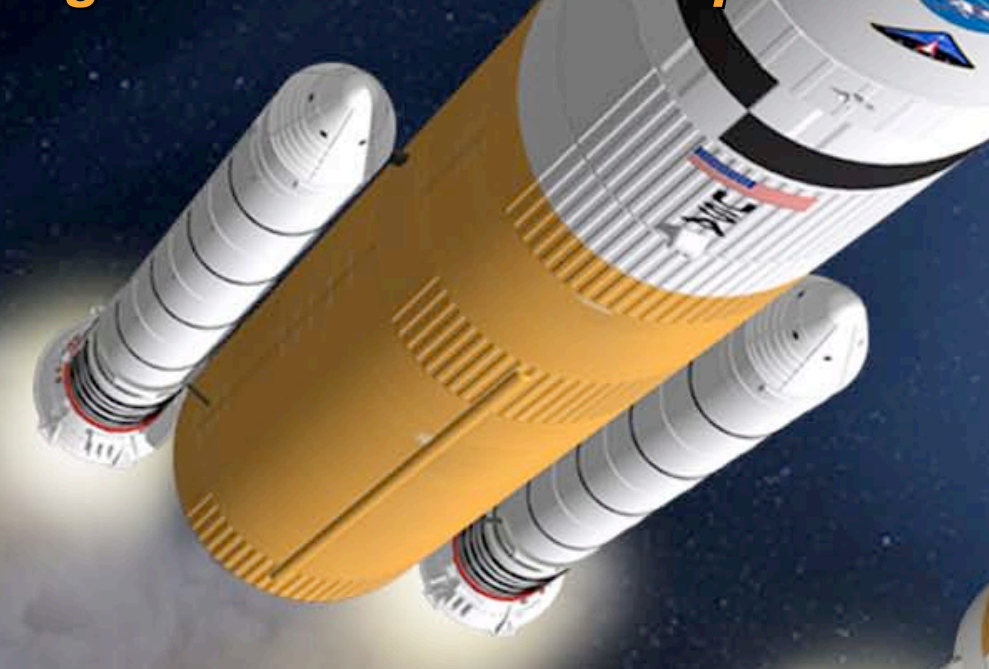

Christopher E. Singer Deputy Director

Engineering Directorate

NASA Marshall Space Flight Center

May 15, 2008 


\section{Agenda}

$\checkmark$ NASA's Mission

$\checkmark$ The NASA Team

$\checkmark$ Why Explore the Moon?

$\checkmark$ NASA's Exploration Roadmap

$\checkmark$ NASA's Exploration Fleet

Why is Operability Important?

$\checkmark$ Shuttle Experience

$\checkmark$ Marshall Space Flight Center's Assignments

$\checkmark$ Marshall Space Flight Center's Capabilities

$\diamond$ Test Flight Philosophy.

$\diamond$ For More Information 


\section{NASA's Mission}

Safely fly the Space Shuttle until 2010

- Complete the International Space Station (ISS)

$\checkmark$ Develop a balanced program of science, exploration, and aeronautics

- Develop and fly the Orion Crew Exploration Vehicle

$\checkmark$ Land on the Moon no later than 2020

- Promote international and commercial participation in exploration

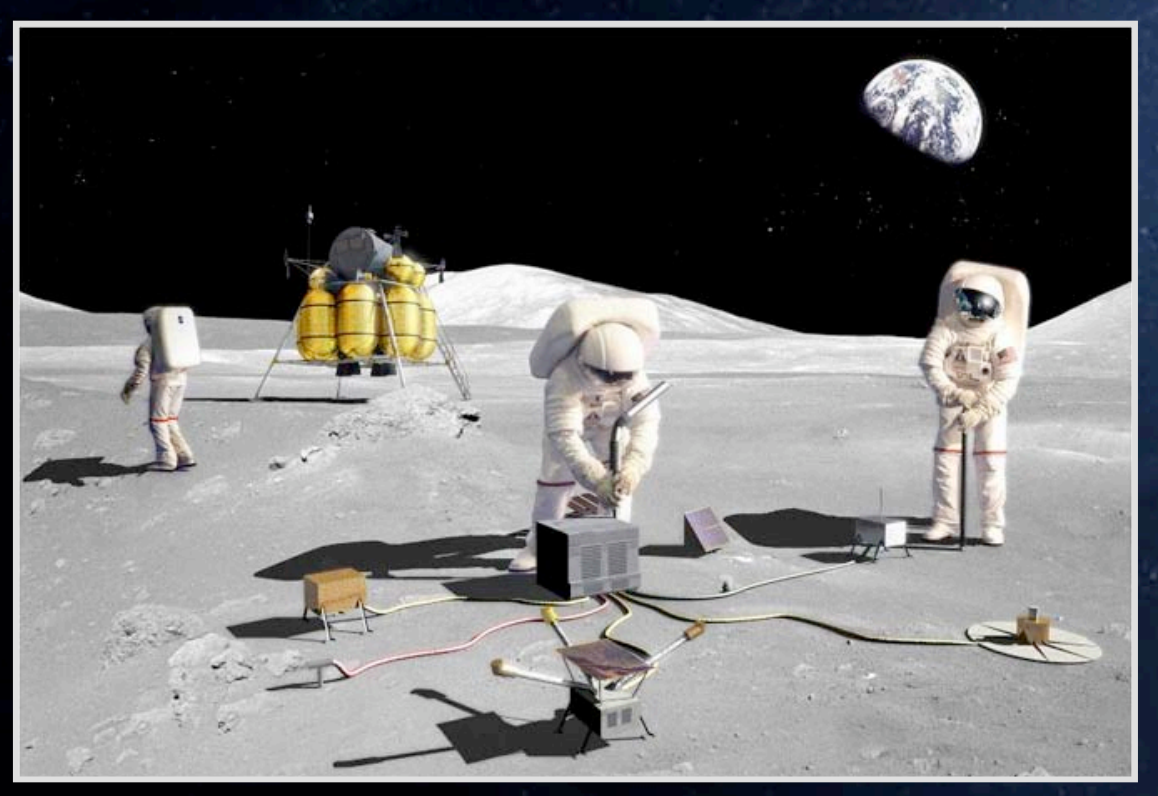

"The next steps in returning to the Moon and moving onward to Mars, the near-Earth asteroids, and beyond, are crucial in deciding the course of future space exploration. We must understand that these steps are incremental, cumulative, and incredibly powerful in their ultimate effect." 


\section{The NASA Team}

National Aeronautics and Space Administration Created by Congress inc $1.5 \%$

$\checkmark$ Marshall Space Flight Center established in 1960

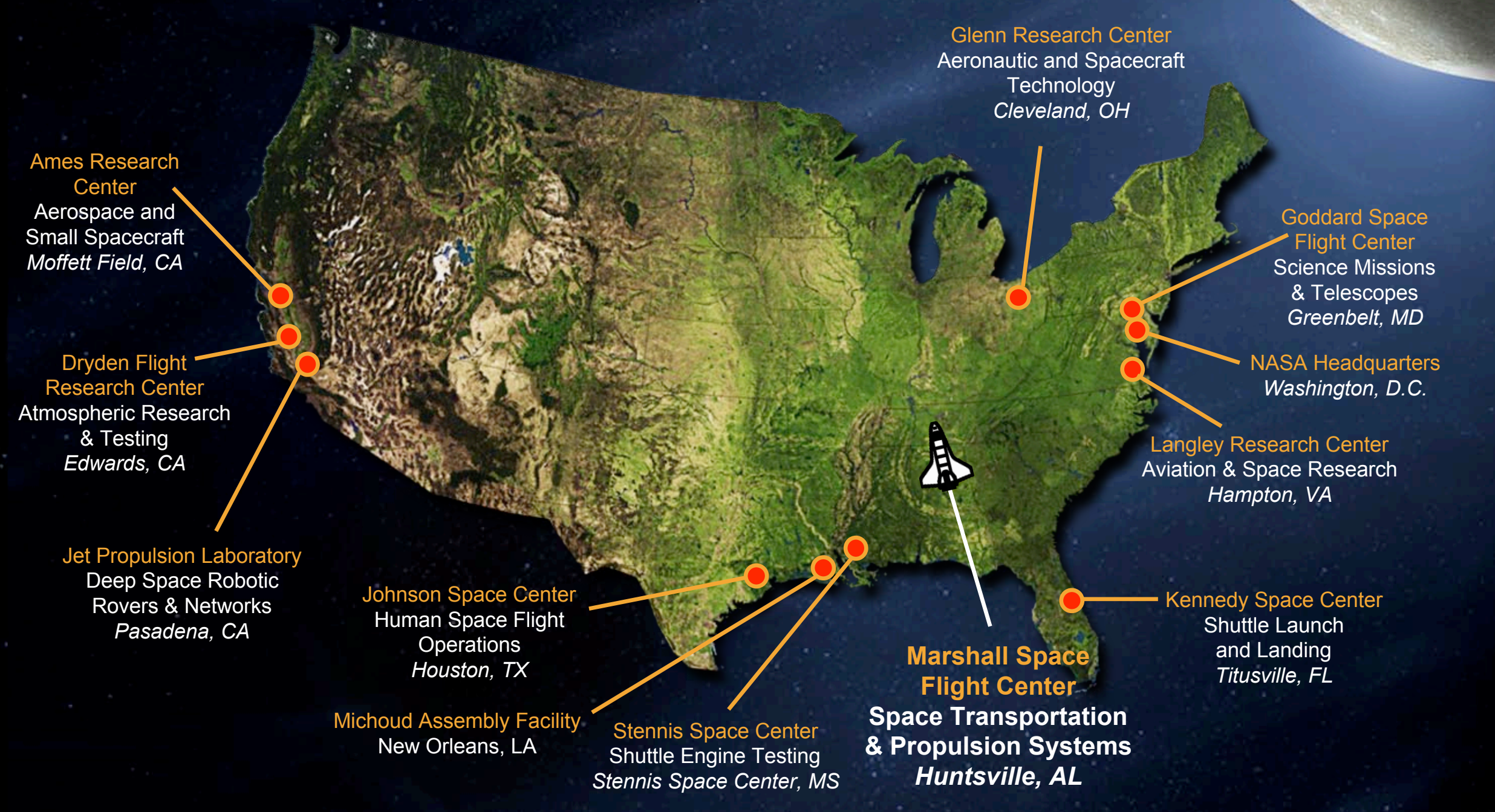

Government, Industry, Academic, and International Partners 


\section{Why Explore The Moon?}

- Lunar missions allow us to:

- Gain exploration experience

- Space no longer a short-term destination

- Will test human support systems

- Use Moon to prove ability to build and repair long-duration space assets

- Develop exploration technologies

- Launch and exploration vehicles

- In-situ resource utilization

- Power and robotic systems

- Conduct fundamental science

- Astronomy, physics, astrobiology, geology, exobiology

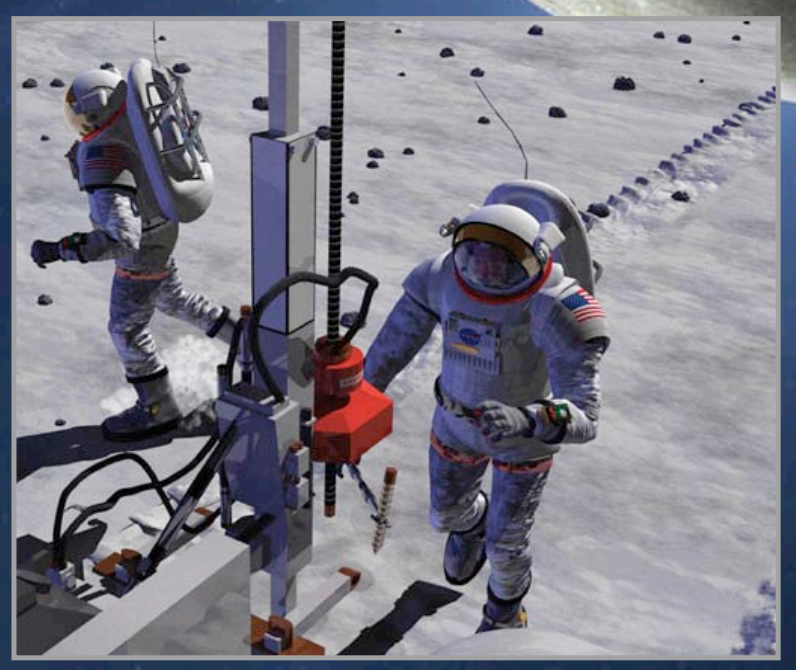

Exploring New Worlds to Improve Our Own

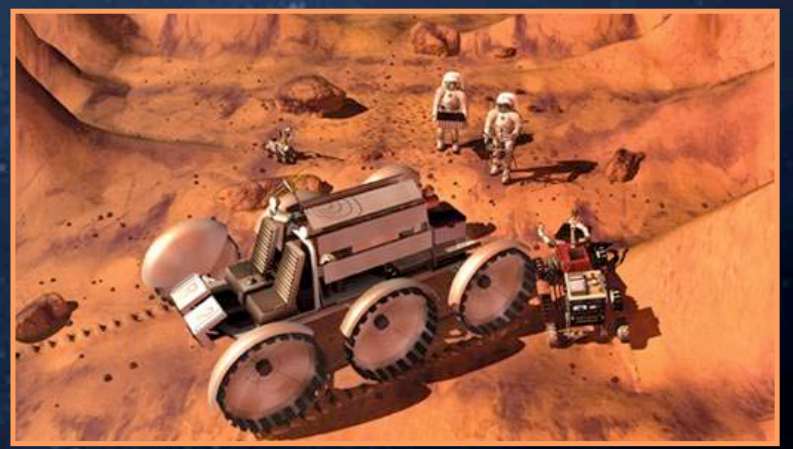




\section{NASA's Exploration Roadmap}

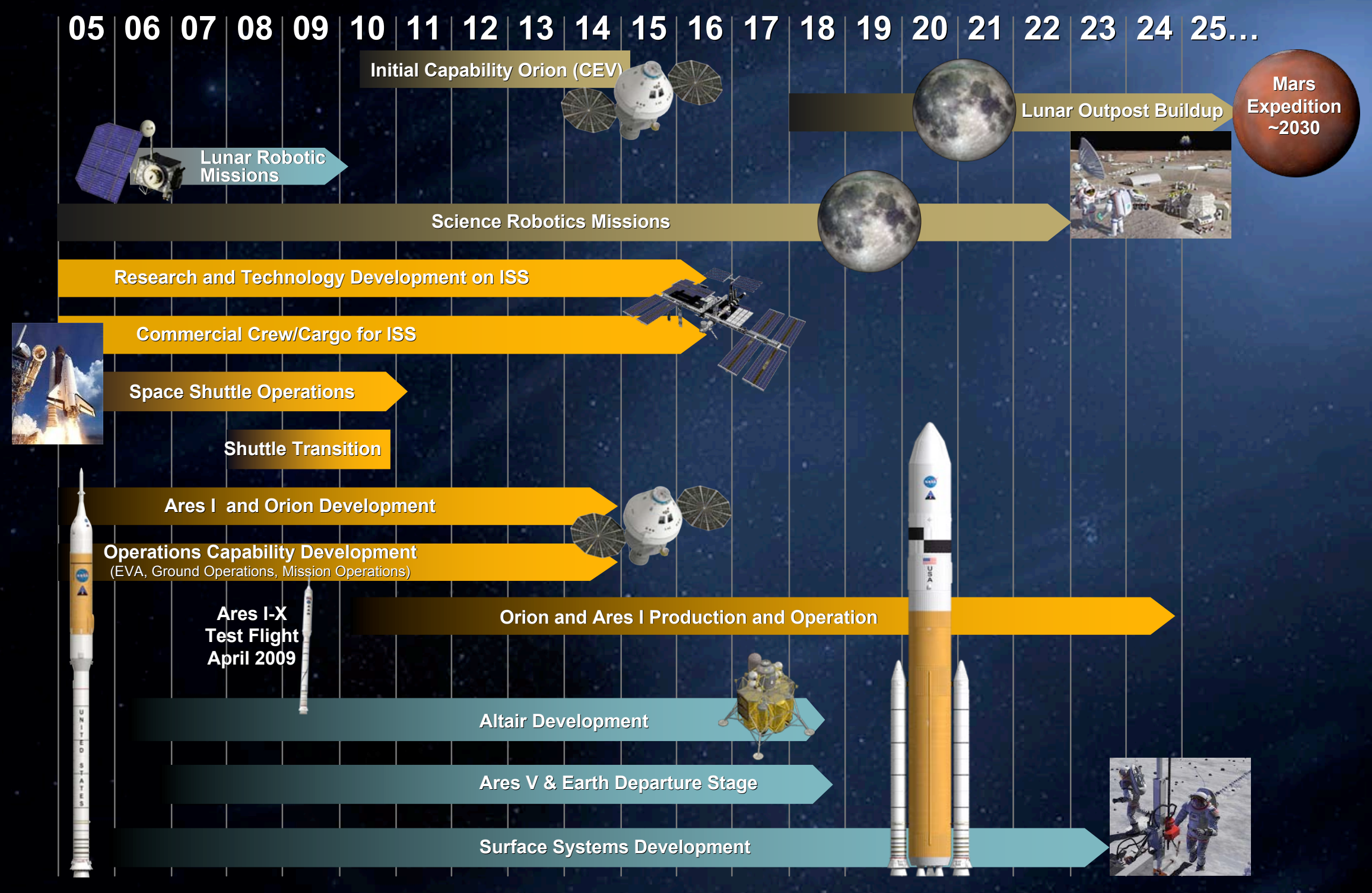

Applying 50 Years of Lessons to a Multi-decade Investment 


\section{NASA's Exploration Fleet}

\section{Earth Departure Stage

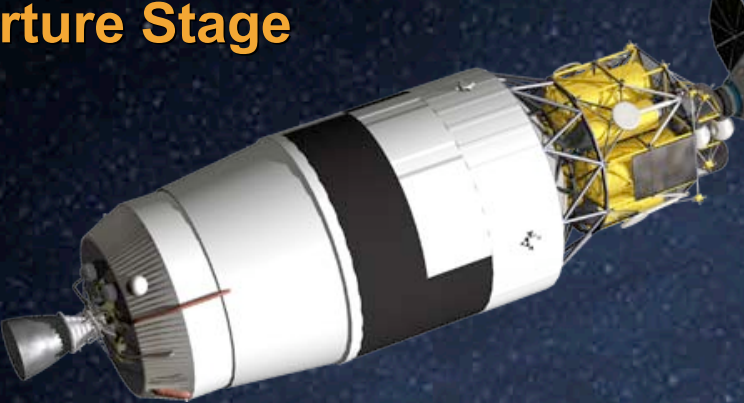

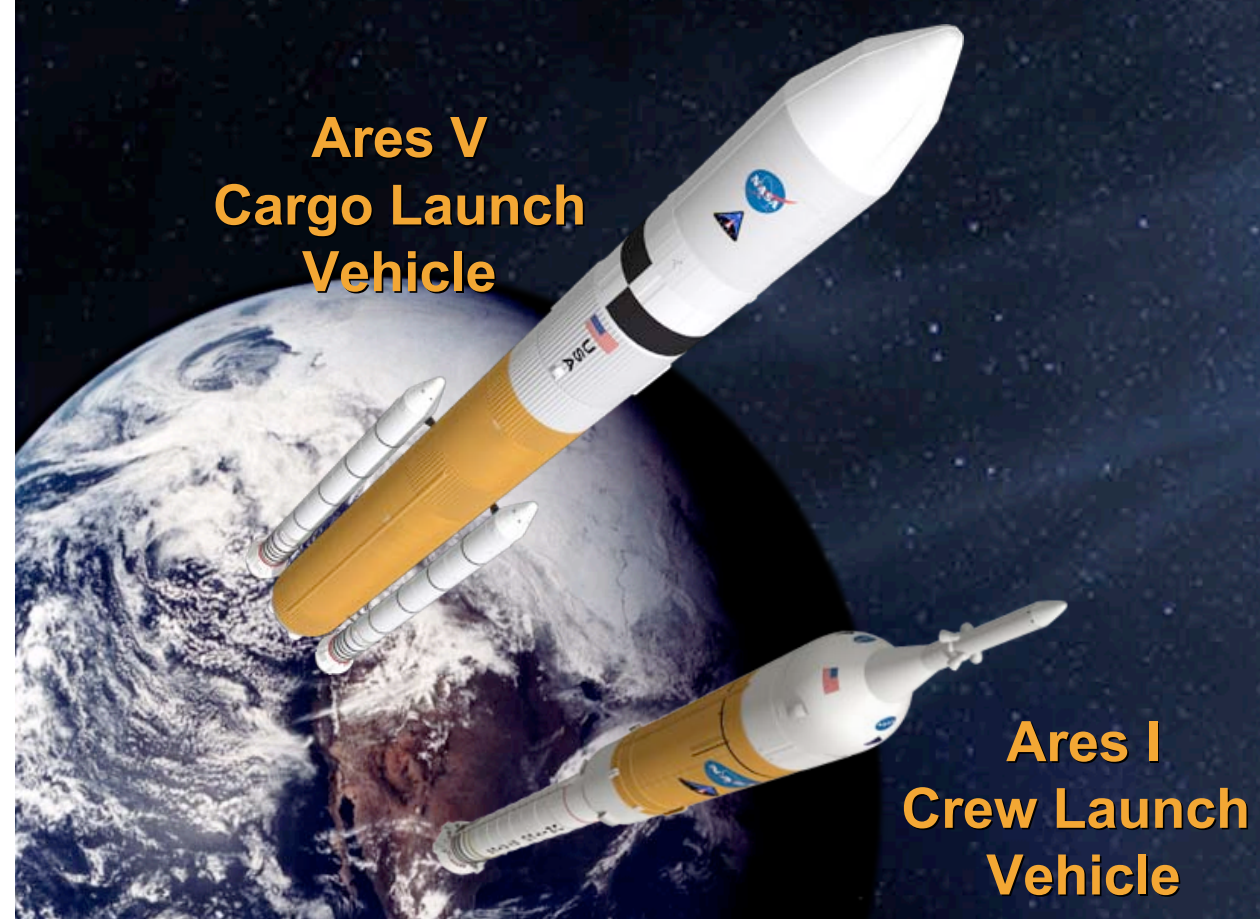

Orion

Crew. Exploration

Vehicle

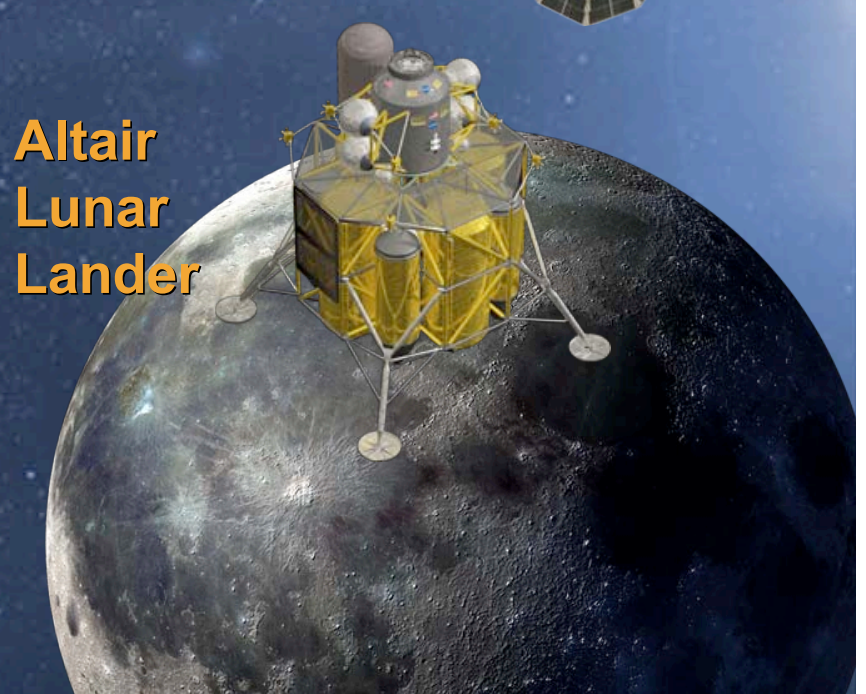

1 48504

What Key Requirements are Safety, Rellability, and Affordability 


\section{Why is Operability Important?}

$\checkmark$ Affordability: Life cycle cost is in consonance with long-range investment \& mission plans

$\checkmark$ Availability: Probability that a system or piece of equipment will operate satisfactorily when needed

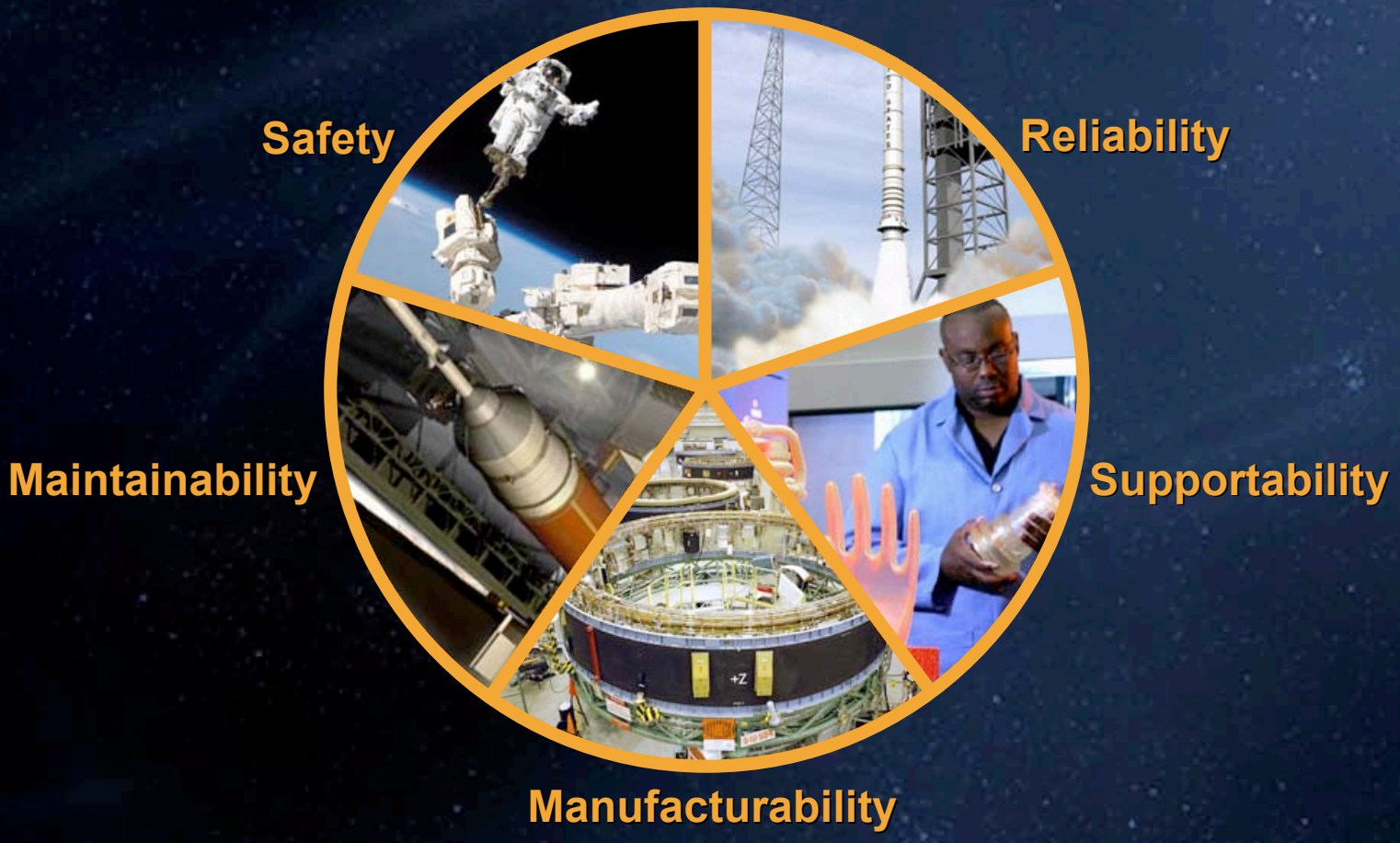

NASA's operability requirement will reduce costs to foster long-term, and long-range, space exploration. 


\section{Shuttle Experience}

$\checkmark$ Requirements

- Reusability

- 60 flights per year capability

- Land at multiple sites.

$\checkmark$ Reality

- Operability traded

- 4 flights per year

- 3 possible landing sites

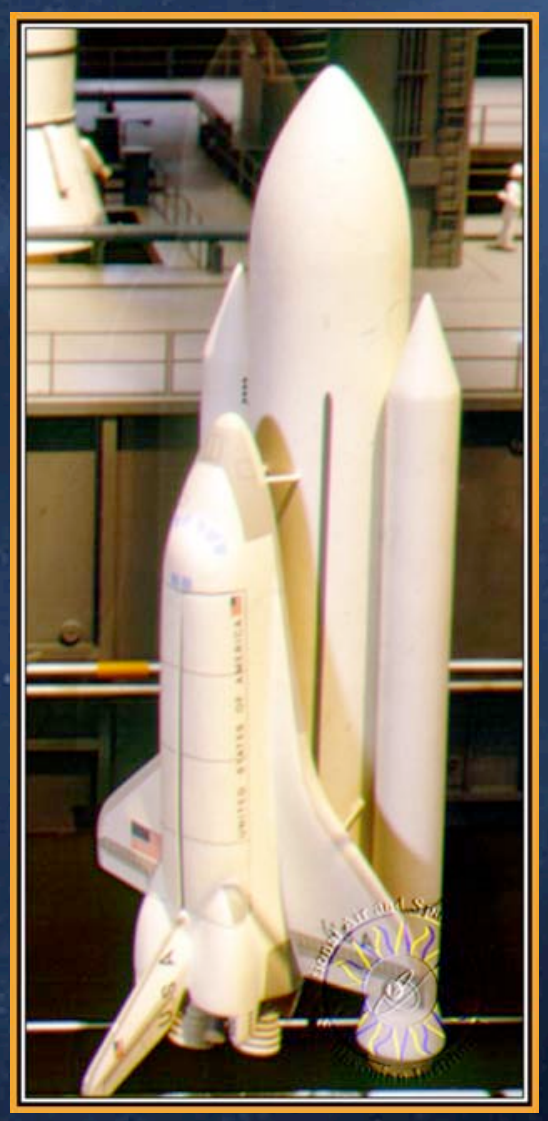

1972: Reusable orbiter and solid rocket boosters, expendable fuel tank, and larger payload bay.

Requirements must be locked down and operability designed into the vehicle system to reduce recurring costs. 


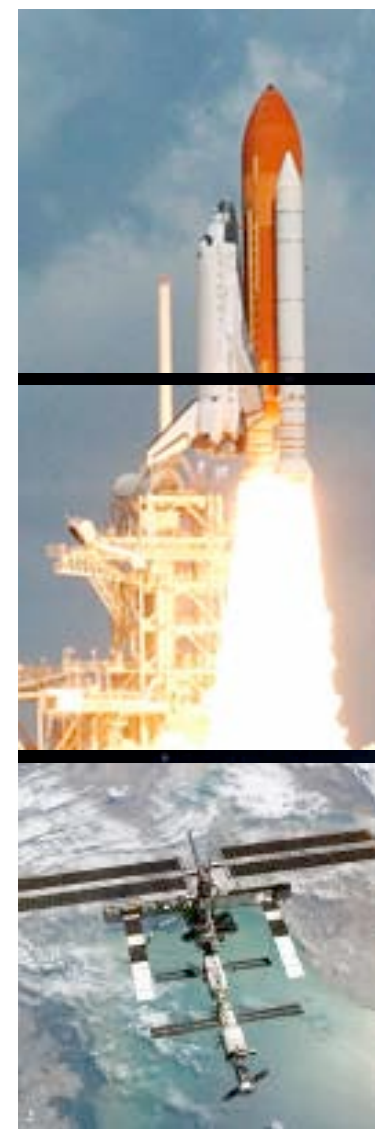

\section{Marshall Space Flight Center's Assignments}

- Manages key Shuttle propulsion hardware and technologies

- Supports round-the-clock science operations on the International Space Station; element integration; and hardware and payload development

$\checkmark$ Provides expertise in science disciplines, including planetary/lunar, Earth, and high-energy astrophysical sciences

- Developing Ares I Crew Launch and Ares V Cargo Launch Vehicles; support to Orion's Launch Abort Systems and Service Modules

$\checkmark$ Supports Lunar Exploration

- Manages the Lunar'Precursor Robotics Program

- Element lead for descent stage of Altair Lunar Lander

- Subsystem lead for descent stage propulsion of Altair Lunar Lander

- Subsystem support for ascent stage propulsion of Altair Lunar Lander

- Support to Lunar Surface Systems

Systems Developer and Integrator for Exploration, Operations, and Science Missions 


\section{Marshall Space Flight Center's Capabilities}

- Vehicle and Spacecraft Development

- Systems Engineering and Integration

- Modeling and Simulation

- Guidance, Navigation, and Control

$\checkmark$ Mission Operations

- Operations Concepts

- Ground Systems

- Flight Operations

$\checkmark$ Materials and Processes

- Metallics/Composites

- Environmental Effects

- Lean/Six Sigma Processes

$\diamond$ Testing

- Propulsion

- Structural

- Shock and Vibration

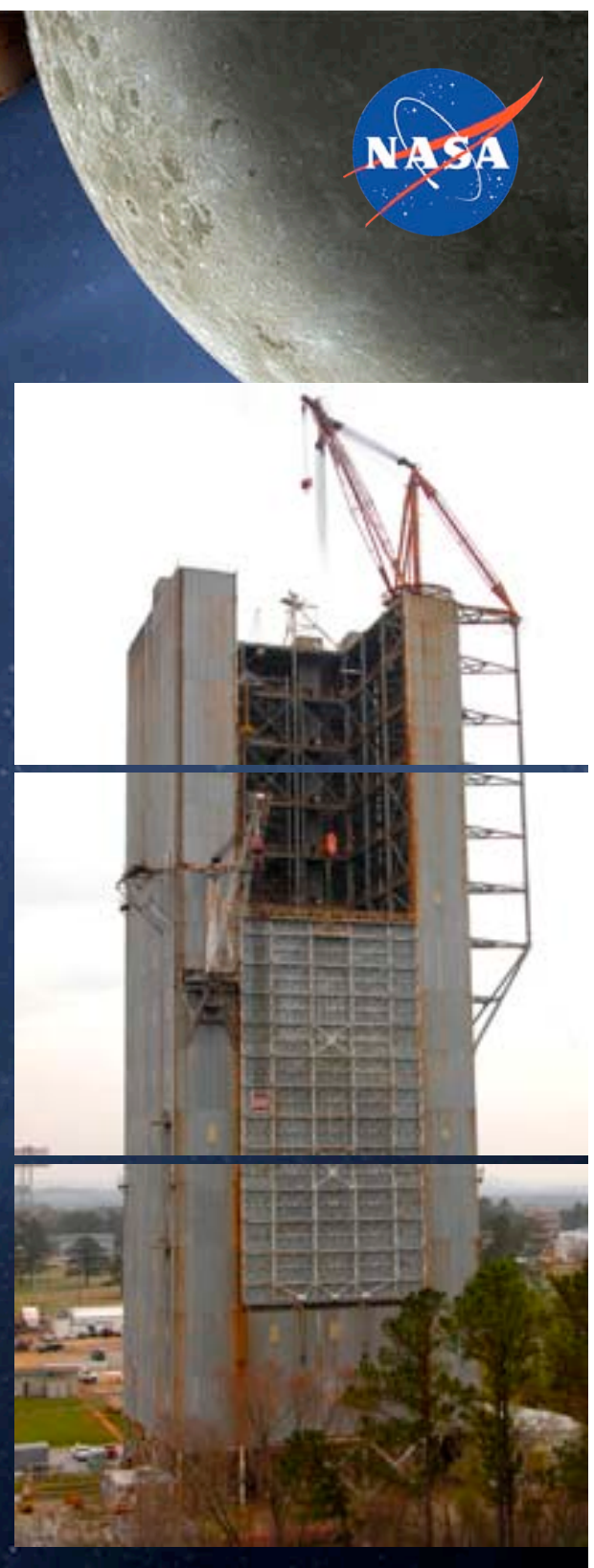

Transitioning and Transforming Infrastructure and Systems for Sustainable Exploration Solutions 


\section{Test Flight Philosophy}

Target Launch Date April 2009

- Informs Ares I Preliminary Design Review Early 2010

Suborbital flight to demonstrate and collect key data:

- Vehicle integration, assembly, and launch operations

- Staging/separation

- Roll and overall vehicle control

- Aerodynamics and vehicle loads

- First stage entry dynamics for recovery

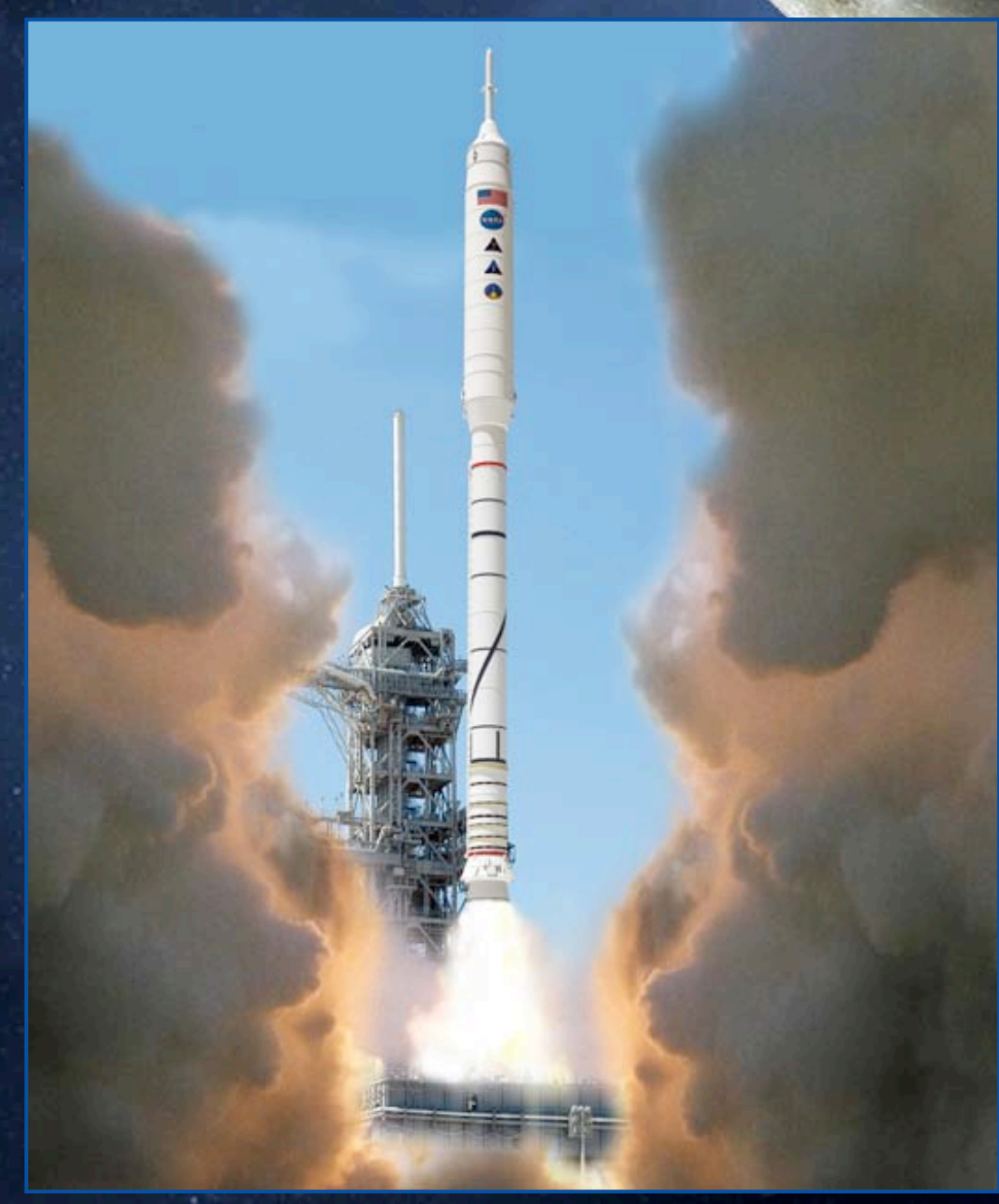

Validates Modeling and Simulation, and Tests Operations Concepts 


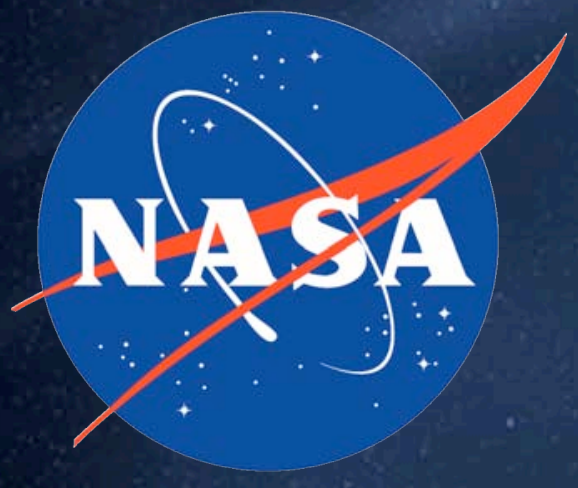

www.nasa.gov 